Review

\title{
The relationship between genetic risk variants with brain structure and function in bipolar disorder: A systematic review of genetic-neuroimaging studies
}

\author{
Licia P. Pereira ${ }^{\mathrm{a}}$, Cristiano A. Köhler ${ }^{\mathrm{a}}$, Rafael T. de Sousa ${ }^{\mathrm{b}}$, Marco Solmi ${ }^{\mathrm{c}, \mathrm{d}}$, Bárbara P. de Freitas ${ }^{\mathrm{a}}$, \\ Michele Fornaro $^{\mathrm{e}}$, Rodrigo Machado-Vieira ${ }^{\mathrm{b}}$, Kamilla W. Miskowiak ${ }^{\mathrm{f}}$, Eduard Vieta ${ }^{\mathrm{g}}$, \\ Nicola Veronese $^{\mathrm{d}, \mathrm{h}}$, Brendon Stubbs ${ }^{\mathrm{d}, \mathrm{i}, \mathrm{j}, \mathrm{k}}$, André F. Carvalho ${ }^{\mathrm{a}, \mathrm{d}, *}$ \\ a Department of Clinical Medicine and Translational Psychiatry Research Group, Faculty of Medicine, Federal University of Ceará, Fortaleza, CE, Brazil \\ b Experimental Therapeutics and Pathophysiology Branch, National Institute of Mental Health, NIH, Bethesda, MD, USA \\ c Department of Neuroscience, University of Padova, Padova, Italy \\ d Institute for Clinical Research and Education in Medicine (IREM), Padova, Italy \\ e New York State Psychiatric Institute (NYSPI), Columbia University, New York, NY, USA \\ ${ }^{\mathrm{f}}$ Copenhagen Psychiatric Centre, Copenhagen University Hospital, Rigshospitalet, Denmark \\ ${ }^{g}$ Bipolar Unit, Hospital Clinic, University of Barcelona, IDIBAPS, CIBERSAM, Barcelona, Catalonia, Spain \\ h National Research Council, Neuroscience Institute, Aging Branch, Padova, Italy \\ i Physiotherapy Department, South London and Maudsley NHS Foundation Trust, Denmark Hill, London SE5 8AZ, United Kingdom \\ ${ }^{\mathbf{j}}$ Health Service and Population Research Department, Institute of Psychiatry, Psychology and Neuroscience, King's College London, De Crespigny Park, London, SE5 8AF, \\ United Kingdom \\ ${ }^{\mathrm{k}}$ Faculty of Health, Social Care and Education, Anglia Ruskin University, Bishop Hall Lane, Chelmsford CM1 1SQ, United Kingdom
}

\section{A R T I C L E I N F O}

\section{Keywords:}

Bipolar disorder

Genetic polymorphisms

Neuroimaging

Magnetic resonance imaging

Functional MRI

Diffusion tensor imagingvoxel based

morphometry

\begin{abstract}
A B S T R A C T
Genetic-neuroimaging paradigms could provide insights regarding the pathophysiology of bipolar disorder (BD). Nevertheless, findings have been inconsistent across studies. A systematic review of gene-imaging studies involving individuals with BD was conducted across electronic major databases from inception until January 9th, 2017. Forty-four studies met eligibility criteria ( $N=2122 \mathrm{BD}$ participants). Twenty-six gene variants were investigated across candidate gene studies and 4 studies used a genome-wide association approach. Replicated evidence (i.e. in $>2$ studies) suggests that individuals with BD carrying the BDNF Val66Met risk allele could have reduced hippocampal volumes compared to non-carriers. This review underscores the potential of geneneuroimaging paradigms to provide mechanistic insights for BD. However, this systematic review found a single replicated finding. Suggestions to improve the reproducibility of this emerging field are provided, including the adoption of a trans-diagnostic approach.
\end{abstract}

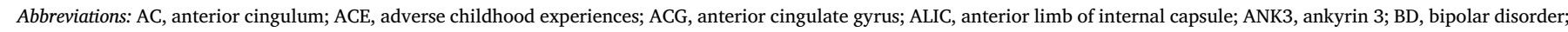

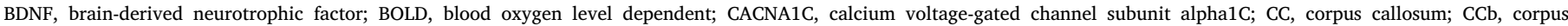

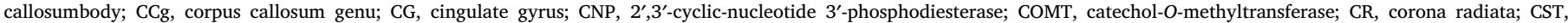

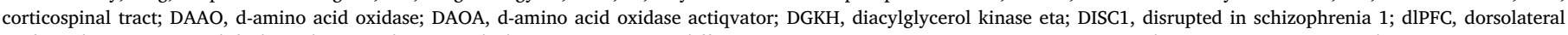

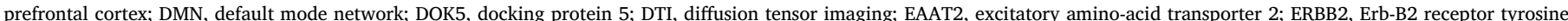

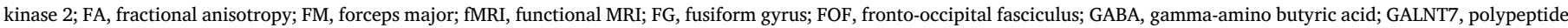

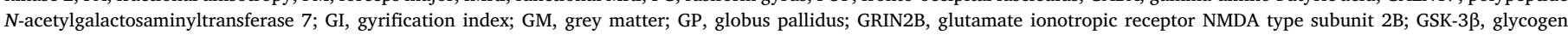

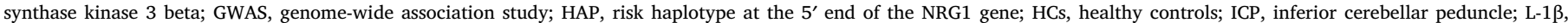

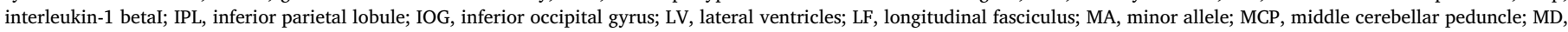

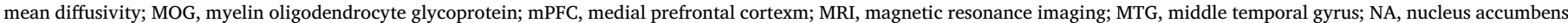

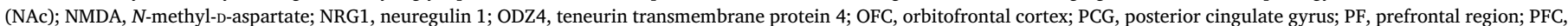

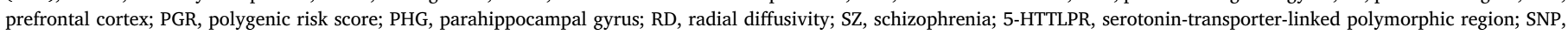

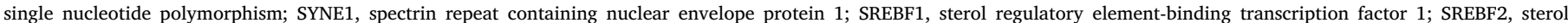

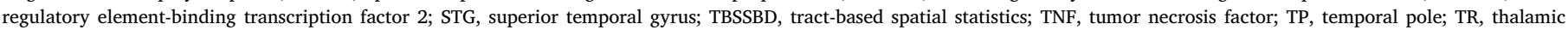
radiation; UF, uncinate fasciculus; VBM, voxel-based morphometry; vlPFC, ventrolateral prefrontal cortex; WM, white matter; ZNF804A, zinc finger protein 804A

* Corresponding author at: Department of Clinical Medicine, Faculty of Medicine, Federal University of Ceará, Rua Prof. Costa Mendes, 1608, $4^{\circ}$ andar, Fortaleza, 60430-040, Brazil.

E-mail addresses: andrefc7@terra.com.br, andrefc7@hotmail.com (A.F. Carvalho). 


\section{Introduction}

Bipolar disorder (BD) may affect approximately $2.4 \%$ of the population worldwide, and is associated with significant disability and elevated mortality rates compared to the general population (Grande et al., 2016; Hayes et al., 2015; Merikangas et al., 2011). The pathophysiology of BD has not been completely elucidated, and the current state of knowledge on putative mechanisms underpinning different clinical features and illness trajectories is limited (Craddock and Sklar, 2013; Hasler and Wolf, 2015). Several lines of evidence indicate that hereditary factors play a relevant role in the pathoetiology of BD, with phenotypic concordance rates ranging from 40 to $70 \%$ in monozygotic twins, and $8-10 \%$ in first-degree relatives (FDRs) (Kerner, 2014; Smoller and Finn, 2003). Genome-wide significant loci for BD have emerged from meta-analyses of GWAS, while loci near the TRANK1, ANK3, ODZ4, CACNA1C, and NCAN genes had at least one additional replication (Goes, 2016; Green et al., 2013; Muhleisen et al., 2014). A recent GWAS identified two additional novel loci associated with bipolar disorder i.e. an inter-genic region on 9p21.3 and markers within ERBB2 (Hou et al., 2016). In addition, the CACNA1C gene differed in expression in the prefrontal cortex of patients with $\mathrm{BD}$ compared to controls (Nurnberger et al., 2014). However, identified genome-wide significant signals seem to explain a low proportion of phenotypic variance of BD (Goes, 2016), and a polygenic risk score accounts for only $3 \%$ of its phenotypic variance (Group, 2011). It has been proposed that the effects of risk genes for BD could be larger and more evident on intermediate phenotypes neurobiologically linked to the disorder, thus providing an impetus to the emergence of 'gene imaging' studies in the literature (Bigos and Weinberger, 2010; Gurung and Prata, 2015; Ivleva et al., 2010).

Precise mechanisms through which genetic variations may influence neural pathways accounting for the phenotypic heterogeneity of BD are yet to be established. Significant efforts have been conducted to identify phenotypic characteristics that are thought to lie more proximal to the genetic factors (i.e. endophenotypes) with the aim that this approach would aid in the identification of biological mechanisms of BD (Gottesman and Gould, 2003; Kurnianingsih et al., 2011). In this context, a large body of literature indicates that BD is associated with significant functional and structural neuroimaging alterations (Kempton et al., 2011; Kupferschmidt and Zakzanis, 2011). Furthermore, meta-analytic evidence indicates that functional and structural neuroimaging abnormalities may be evidence in individuals at-risk for BD (Fusar-Poli et al., 2012), and a recent systematic review indicates that functional and structural neuroimaging abnormalities are also evident in healthy FDRs of patients with BD (Piguet et al., 2015). Altogether this literature provides support to the view that subtler functional and structural neuroimaging abnormalities in at-risk individuals could represent vulnerability markers of BD. 'Imaging genetics' has emerged as a field with an underlying rationale that genetic variations that confer risk to mental disorders may exhibit higher penetrance at such brain functional/structural alterations than at the more distal psychopathological/behavioral levels (Hashimoto et al., 2015; Rasetti and Weinberger, 2011). Hence, an ever-increasing number of studies has attempted to investigate the associations between genetic variations expected to play a pathophysiological role in $\mathrm{BD}$ and structural and functional neuroimaging abnormalities. However, different age groups, neuroimaging modalities, treatment-related effects and investigated genes (or polygenic risk scores) are potential confounders which might have contributed to the heterogeneity of studies so far (Kurnianingsih et al., 2011). To overcome such a strong heterogeneity a systematic review of 'neuroimaging genetics' studies which considered genes which have been previously found to reach genome-wide significance in schizophrenia and BD was conducted (Gurung and Prata, 2015; Lee et al., 2012). However, this previous systematic review considered studies performed solely in healthy individuals, while only seven studies performed in samples with BD were included (Gurung and Prata, 2015). A comprehensive systematic overview focusing on 'imaging genetics' specifically in people with BD is currently lacking.

Therefore, our systematic review aims to provide a comprehensive and up-dated synthesis of all available 'imaging genetics' literature in BD. Both structural and functional magnetic resonance imaging studies will be considered. Our goal was two-fold: (1) to summarize and facilitate the integration of findings in this evolving field; and (2) to provide an illustrative structural and functional brain map of significant $\mathrm{BD}$-associated gene risk variants, which are expected to be linked to brain regions with known alterations in BD.

\section{Methods}

A systematic literature search of genetic variations and functional and structural magnetic resonance imaging (MRI) studies in BD was conducted. We followed the Preferred Reporting Items for Systematic Reviews and Meta-Analyses (PRISMA) statement (Moher et al., 2010), using an a priori defined but unpublished protocol.

\subsection{Search strategy}

The EMBASE, PubMed/MEDLINE and PsycINFO electronic databases were searched from inception up to January 9th, 2017. The following search string was used: (bipolar disorder OR mania OR bipolar depression) AND (structural magnetic resonance OR functional magnetic resonance OR AMRI OR BOLD fMRI OR magnetic resonance imaging OR magnetic resonance neuroimaging OR tractography) AND (SNPs OR single nucleotide polymorphism OR haplotypes OR gene expression OR gene OR genetic score OR genetic* OR methylome OR epigenetic* OR genome OR transcriptome OR polymorphism OR genetic polymorphism OR genome wide OR genome-wide). In addition, the reference lists of eligible articles were hand searched to identify additional eligible References

\subsection{Eligibility criteria}

The articles included in this review fulfilled the following criteria: (1) human studies with participants at any age with a diagnosis of type I BD (BD-I), type II BD (BD-II), or BD not otherwise specified (BD-NOS) using standard diagnostic criteria (DSM-IV, ICD-10 or Research Diagnostic Criteria regardless of the current mood state (euthymic, manic or depressed); (2) combined investigations of genetic factors and brain imaging protocols (structural or functional). The included articles had to investigate imaging-genetic associations of $\mathrm{BD}$ patients that were carriers of high-risk alleles compared to either healthy controls (HC) and/or BD patients who were non-carriers of the investigated risk alleles. No language restrictions were applied. Studies that reported a sub-analysis of a well-defined sample of participants with BD within a broad mood disorder group were also eligible.

Animal and post-mortem studies, case series, literature reviews, conference papers, meeting abstracts or meta-analyses were excluded. Studies which included samples with mixed diagnoses were excluded, unless data for participants with BD were separately provided. Articles that used imaging methods other than structural or functional MRI (e.g., magnetic resonance spectroscopy or positron emission tomography) were also excluded.

\subsection{Study selection}

Two investigators (LPP and BPF) independently screened the titles and abstracts of retrieved references for eligibility. Next, the full-texts of the selected references were obtained, and the same authors independently reviewed each article for final inclusion in this systematic review. Disagreements were resolved through consensus. Whenever a consensus could not be achieved, a third author (CAK) made the final 
decision regarding inclusion. The agreement between the two raters was high (83.7\%).

\subsection{Data extraction}

Two authors (LPP and BPF) independently extracted the data of selected papers using a standardized spreadsheet. The following variables were recorded: first author, year of publication, sample size, age of participants, $\%$ of females, diagnostic criteria for BD, genetic assessment (name of the gene, method, SNP and allele groups), imaging methods and procedures, the experimental paradigm (in case of fMRI), MRI regions of interest (ROI) and the results of the association between the genetic variants and each ROI. Whenever the sample contained BD patients as part of a broader sample that included other psychiatric diagnoses, only data and associations of the BD group was extracted. The agreement between the two raters was $89.6 \%$.

\subsection{Data synthesis}

Due to the anticipated heterogeneity and paucity of homogenous studies, meta-analysis of included studies was not feasible. Thus, we synthesized the included studies with a best evidence synthesis. First, we considered structural imaging studies and candidate genes and GWAS relationships. Second, we considered the relationship between functional imaging studies and candidate genes and GWAS studies. We considered evidence to be replicated or consistent when a relationship was evident between 2 studies between a candidate gene/GWAS and a particular structural and/or functional neuroimaging abnormality.

\section{Results}

\subsection{Search results}

The literature search found 873 records, and 9 additional references were found through searching the reference lists of included articles. After the removal of duplicates, 632 unique references were screened. Five hundred and seventy-one references were excluded after title/ abstract screening. Of the 61 full-texts assessed, 17 were excluded due to: (1) not an original study $(\mathrm{k}=2)$; (2) no data for BD participant was provided $(\mathrm{k}=9)$, (3) not investigating samples with $\mathrm{BD}(\mathrm{k}=1)$, (4) no genetic measure $(\mathrm{k}=1)$, (5) using other neuroimaging method not specified in the inclusion criteria $(\mathrm{k}=2),(6)$ not investigating geneticimaging associations in BD $(\mathrm{k}=1)$ or $(7)$ article not available $(\mathrm{k}=1)$. Therefore, forty-four genetic-neuroimaging studies met inclusion criteria for this qualitative systematic review. Fig. 1 presents the flowchart of study selection. The studies excluded during full-text review and reasons for exclusion are presented in Supplementary Table S1 that accompanies the online version of this article.

\subsection{Overview of included studies}

All included studies are described in Tables 1 and 2 (structural MRI, $\mathrm{k}=28$ ) and Tables 3 and 4 (fMRI, $\mathrm{k}=16$ ). Forty studies investigated 26 candidate risk genes for BD and 4 studies used a genome-wide significance analysis. The studies altogether included 2122 participants with BD [BD group; age $=38.6 \pm 13.6$ years (mean \pm SD); $56.6 \%$ female] and 2389 healthy participants (HC group; age $=35.9 \pm 12.4$ years (mean \pm SD); $53.0 \%$ female). All studies included only adult samples except for three studies that included only pediatric samples (Barzman et al., 2014; Liu et al., 2010; Zeni et al., 2016). Twenty-eight studies investigated structural changes using either VBM or DTI, and 16 studies used functional MRI to investigate changes in brain activity associated. The functional studies were based on several tasks, including emotional processing of faces $(\mathrm{k}=8)$, Posner emotional task $(\mathrm{k}=1)$, verbal fluency tasks $(\mathrm{k}=4)$, and working memory $(\mathrm{k}=2)$. Emotional tasks included contrasts of the task-related activity and baseline, and within neutral and affective content. The other tasks compared task-related activity with baseline.

\subsection{Structural imaging studies}

\subsubsection{Candidate genes}

Twenty-six studies investigated associations of 19 candidate genes with structural imaging data (see Table 1 for studies using VBM and Table 2 for studies using DTI). Except for the study by Zeni et al. (2016), all other studies included an adult sample. Eighteen studies investigated structural measures [total/regional brain volumes, cortical thickness and white matter (WM) integrity] using VBM, 6 studies focused on DTI metrics [e.g. fractional anisotropy (FA)] and 2 studies used both methods. The most frequently investigated genes were $B D N F$ ( 5 studies, all VBM), CACNA1C (5 studies, 4 VBM and 1 DTI), ANK3 (3 studies, 1 VBM and 2 VBM/DTI combined), 5-HTTLPR (3 studies, 2 VBM and 1 DTI), ZNF804A (3 studies, 1 VBM and 2 DTI), and GSK-3 $\beta$ (2 studies, 1 VBM and 1 DTI) (Tables 1 and 2). The remaining genes (EAAT2, DGKH, NRG1, HAP, CNP, MOG, IL-1B, ODZ4, SYNE1, DAOA, GRIN2B, SREBF1 and SREBF2) were investigated by a single study.

Six studies included only participants with BD (i.e. carriers vs. noncarriers of genetic risk variants) (Benedetti et al., 2013; Benedetti et al., 2015a,b; Benedetti et al., 2014; Poletti et al., 2016; Poletti et al., 2014). Three of those studies investigated 5-HTTLPR (Benedetti et al., 2015a), GSK-3 $\beta$ (Benedetti et al., 2013) or SREBF1/2 (Poletti et al., 2016) using DTI. Benedetti et al. (2015a) found that carriers of the 5-HTTLPR S (i.e., short) allele had increased radial and mean diffusivity in several brain white matter tracts, including the cingulum gyrus, corpus callosum (body and genum) and corona radiata compared to non-carriers. Significant increases in axial diffusivity measures were observed in carriers of the less active GSK3- $\beta$ rs334558*C gene-promoter variant in 70 participants with an index bipolar depressive episode across several white matter fiber tracts (Benedetti et al., 2013). Interestingly, lithium treatment (which inhibits GSK-3ß) was also associated with similar changes in axial diffusivity, which points to a better integrity of axon and myelin sheaths (Benedetti et al., 2013). Poletti et al. (2016) found that carriers of the SREBF2 rs1052717 polymorphism A/A genotype had increased radial diffusivity and reduced FA compared to $\mathrm{G}$ carriers in the cingulum, corpus callosum, superior and inferior longitudinal fasciculi, and anterior thalamic radiation. The remaining 3 studies investigated variations in the 5-HTTLPR (Benedetti et al., 2014), GSK$3 \beta$ (Benedetti et al., 2015b) or EAAT2 (Poletti et al., 2014) genes using VBM. All three studies did not verify any significant genetic-imaging associations in BD.

The other 19 studies included a HC comparison group. Fourteen of these studies found significant associations of brain structural changes and genetic variants, in both grey and white matter. These included associations of the BDNF $(\mathrm{k}=4), 5$-HTTLPR $(\mathrm{k}=1)$, CACNAC1 $(\mathrm{k}=1), D G K H(\mathrm{k}=1), N R G 1$ and $H A P_{I C E}$ haplotype $(\mathrm{k}=1), I L-1 \beta$ $(\mathrm{k}=1)$ with brain volumes using VBM, and also ANK3 $(\mathrm{k}=2)$, 5HTTLPR $(\mathrm{k}=1), \operatorname{GSK}-3 \beta(\mathrm{k}=1)$ and GRIN2 B $(\mathrm{k}=1)$ with white matter integrity using DTI. See section 3.5.1 for details.

\subsubsection{Genome-wide association studies}

Two studies used Genome-Wide Association Studies (GWAS) to identify genes associated with $\mathrm{BD}$, and then investigated associations with structural changes using VBM (Bakken et al., 2011; Oertel-Knochel et al., 2015) (Table 1). Oertel-Knochel et al. (2015) investigated 7 SNPs obtained from a GWAS study in SZ (MIR137, CCDC68, CNNM2, NT5C2, MMP16, CSMD1 and PCGEM1) to identify genetic variants associated with structural brain changes across the psychosis spectrum. No statistically significant association was observed for the group that included only participants with BD. Bakken et al. (2011) examined associations of 597,198 SNPs with average cortical thickness using the PLINK analytic tool (Purcell et al., 2007) to fit an additive linear model with minor allele counts, sex, age and diagnosis, using a conservative 

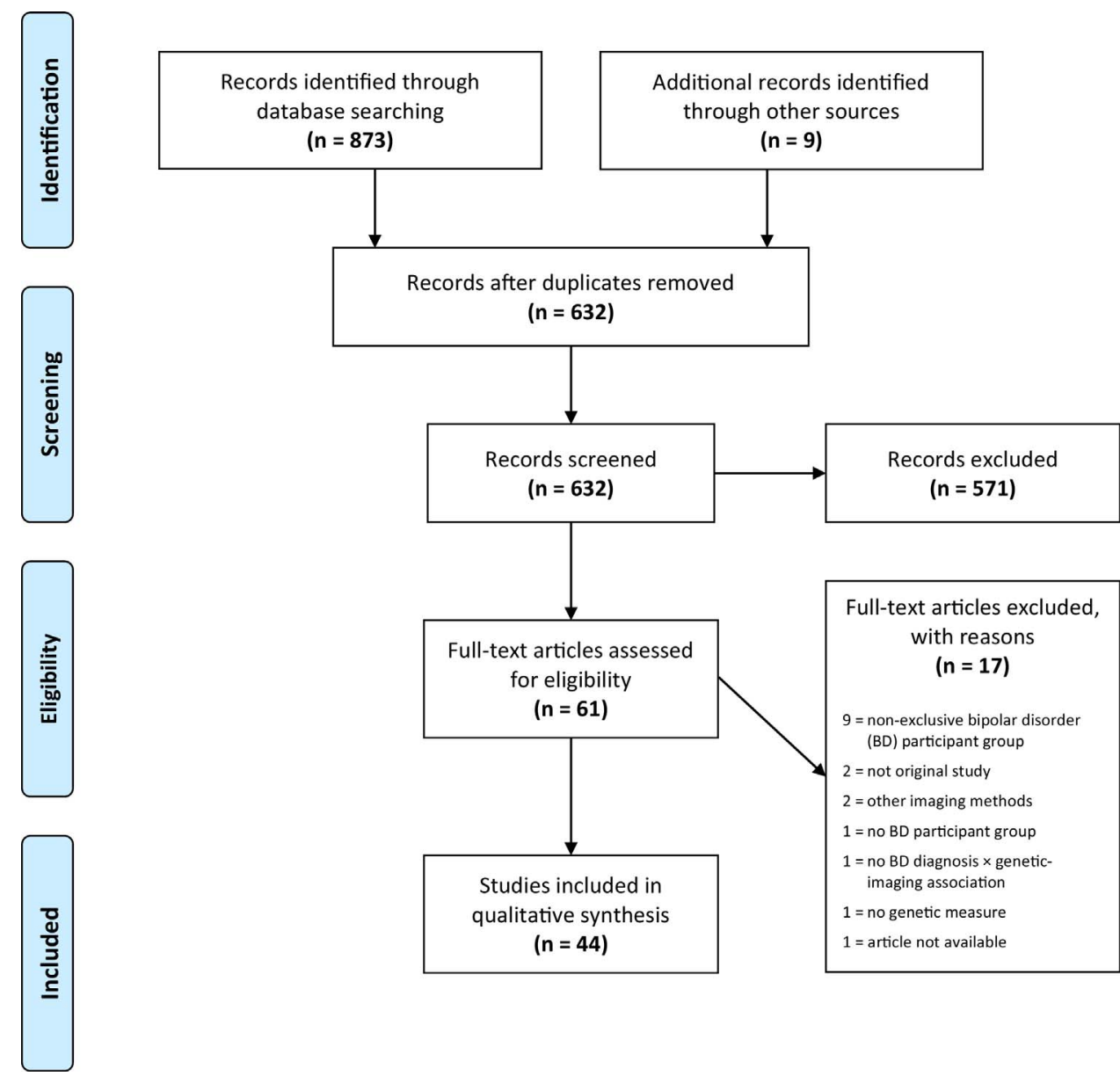

Fig. 1. PRISMA flowchart of the study selection process.

Bonferroni correction for genome-wide significance. No statistically significant imaging-genetic associations were found in the BD group.

\subsection{Functional imaging studies}

\subsubsection{Candidate genes}

Fifteen studies investigated associations of variations in 11 candidate genes and blood oxygen level dependent (BOLD) fMRI. The most frequently investigated genes were CACNA1C (4 studies) and ANK3, $D A A O$ and DISC1 (2 studies each) (Tables 3 and 4). The remaining genes (TNF, G72, BclI, COMT, DOK5, 5-HTTLPR and NRG1) were investigated in a single study.

Barzman et al. (2014) investigated a small sample of pediatric BD patients, and found that the expression of 11 TNF-related genes in peripheral blood mononuclear cells of participants with BD significantly correlated with activation of the amygdala or anterior cingulate gyrus during the affective Posner task.

All other studies included only adults, and included a HC group for comparison. Eight of these studies found significant gene $\times$ brain activity associations in BD patients. The CACNAC1 gene was associated with increased amygdala activation in the face recognition paradigm $(\mathrm{k}=2)$. The ANK3 gene was associated with increased activity in the cingulate cortex during a working memory task $(\mathrm{k}=1)$. Both the ANK3 and CACNAC1 genes were associated with reduced activation of the vlPFC during the emotional facial processing task $(\mathrm{k}=1)$. The DISC1 gene was associated with decreased activation of the IPL and left CG during a verbal initiation and sentence completion task $(\mathrm{k}=1)$. Also in a verbal fluency paradigm, the DAOA $(\mathrm{k}=1)$ genotype was associated with a greater deactivation of the let precuneus in BD patients, while the NRG1 genotype was associated with increased activation of the right posterior OFC. Finally, the 5-HTTPLPR was associated with lower ventral anterior CG activity during emotional processing of faces $(\mathrm{k}=1)$. See section 3.5.2 for details.

\subsubsection{Genome-wide association studies}

Liu et al. (2010) investigated a sample of adolescents with BD and HCs of similar age. These authors performed a GWAS, and found that the rs2023454 SNP of the DOK5 gene was associated with right amygdala activation under contrast to hostility faces although no significant differences between and within BD and HC samples were observed. Dima et al. (2016) calculated a polygenic risk score (PGR) from genes that were associated with BD in a GWAS. Although the PGR was associated with changes in brain activity during a facial processing task and a working memory task in both the BD and HC groups, no statistically significant differences emerged between the two groups or within the BD group as a function of the PGR.

\subsection{Significant genetic-neuroimaging associations in $B D$}

The statistically significant associations reported across geneticneuroimaging studies using candidate genes are shown in Table 5. In addition, a brief synopsis of possible biological functions of gene products is provided.

\subsubsection{Structural VBM and DTI studies}

Statistically significant structural neuroimaging alterations in $\mathrm{BD}$ 


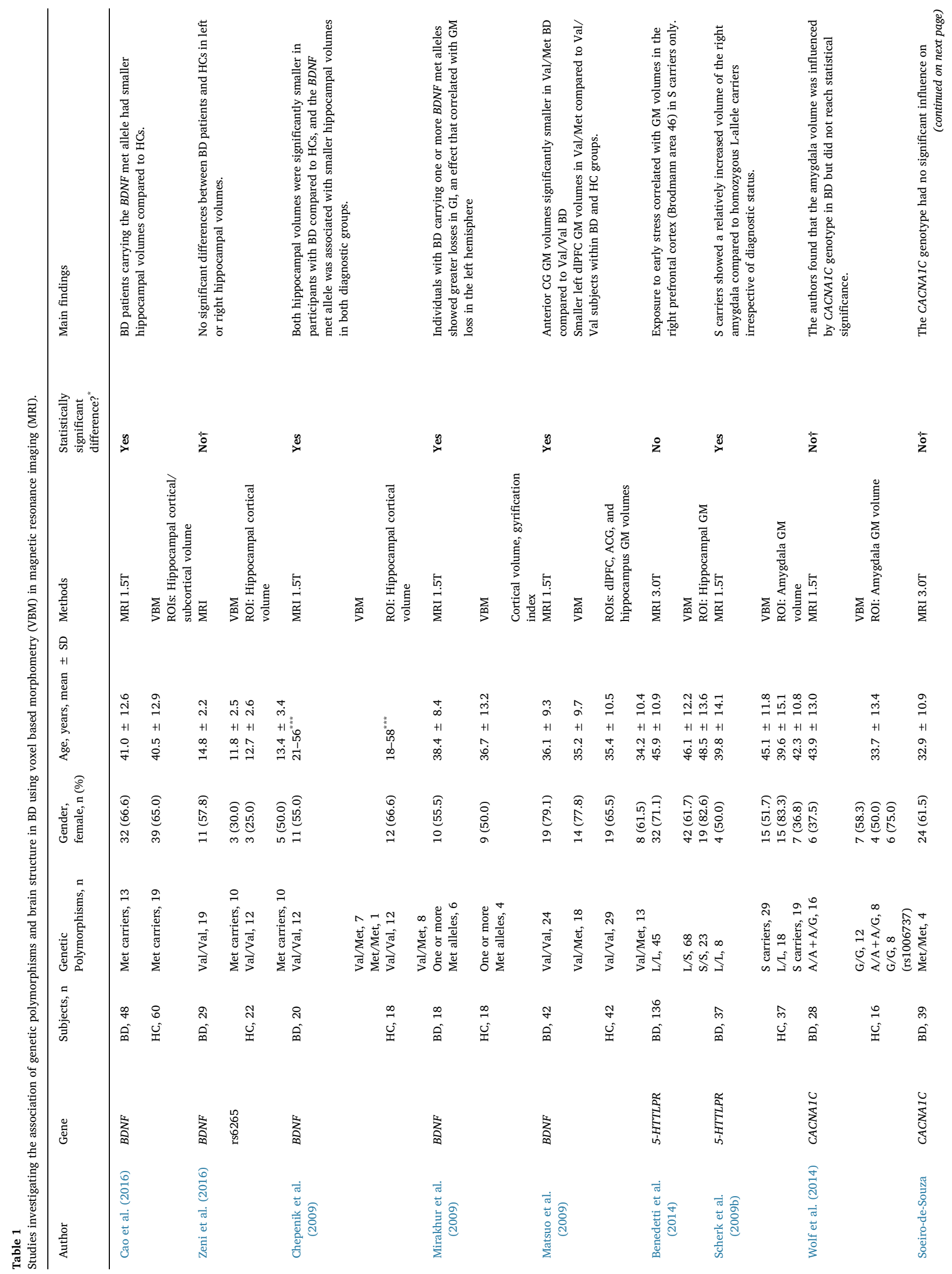




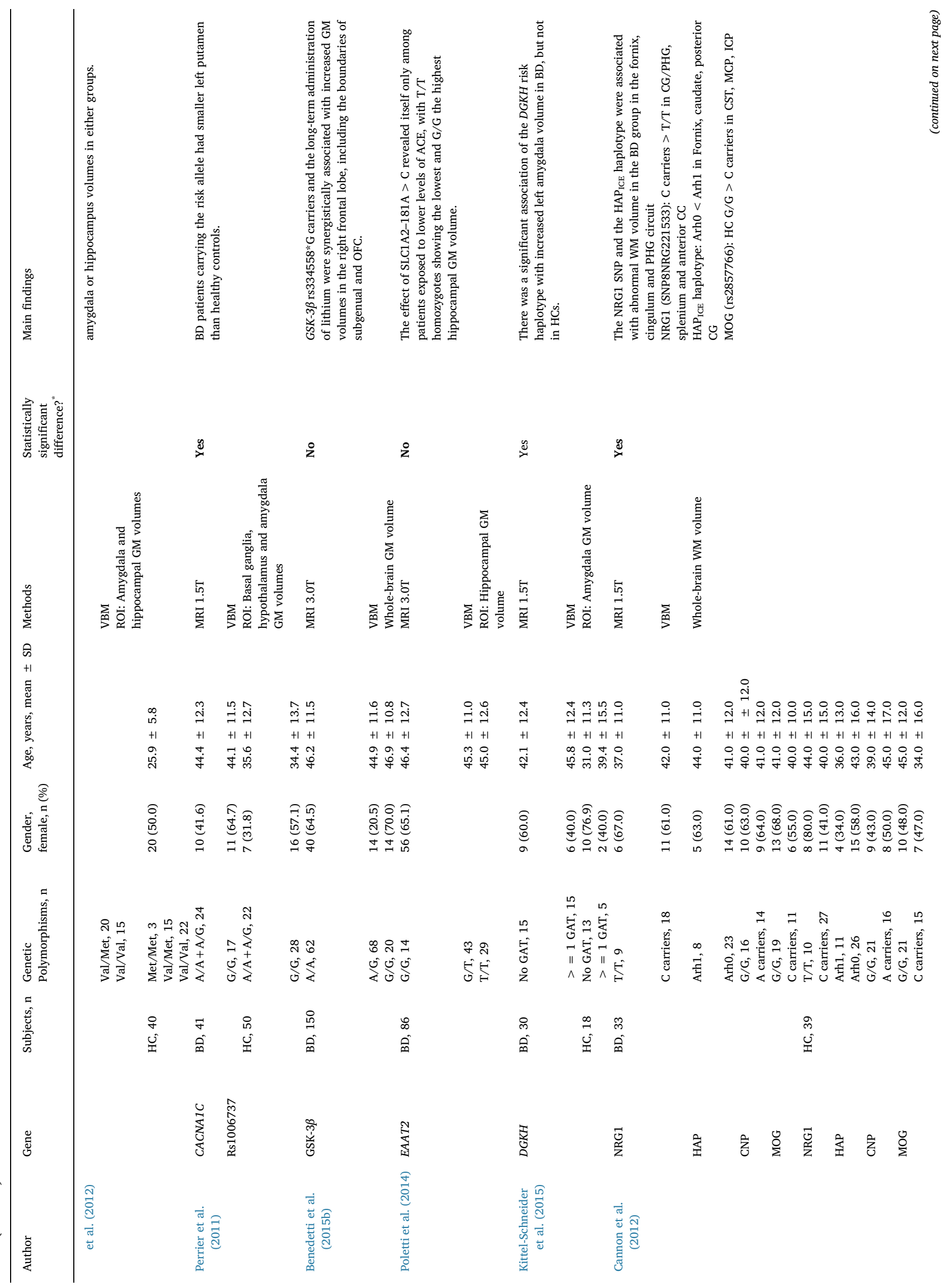




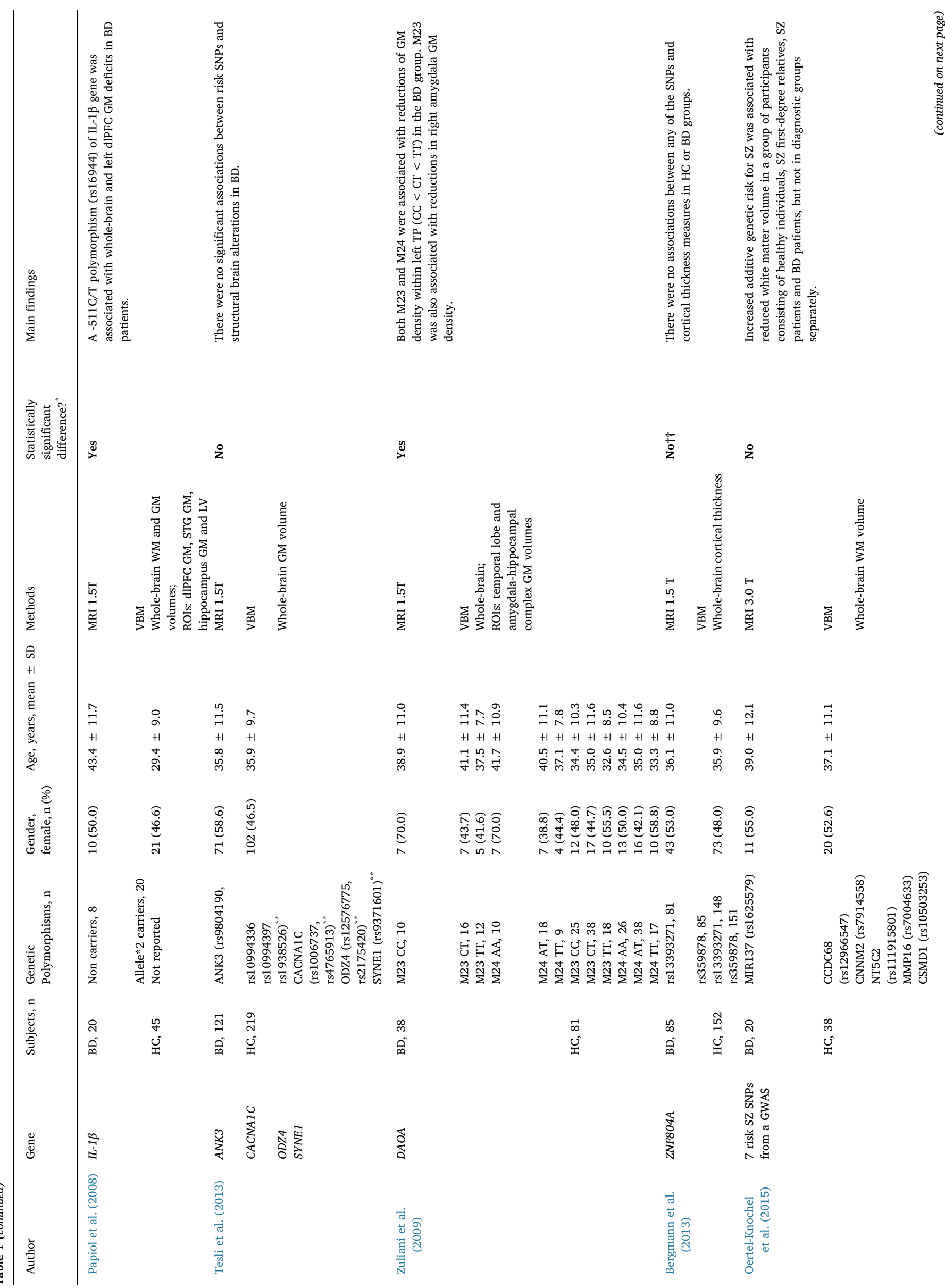


patients were associated with genetic variations of the $B D N F, 5$ HTTLPR, CACNA1C, DGKH, NRG1, IL-1 $\beta, A N K 3$, and GRIN2 B genes (Table 5). Nevertheless, there was a lack of replicated evidence.

Two studies provided evidence that BD patients who carry the Met allele of the BDNF gene may present several structural alterations encompassing several brain areas namely the left and right hippocampus (Cao et al., 2016; Chepenik et al., 2009). A four-year prospective study found that individuals BD participants who were carriers of one or more BDNF Met alleles had significantly greater losses in gyrification indexes, an effect that correlated with gray matter loss in the left hemisphere (Mirakhur et al., 2009). Matsuo et al. (2009) observed smaller bilateral anterior cingulate gyrus volumes in BD patients with $\mathrm{Val} / \mathrm{Met}$ compared to those with Val/Val BDNF genotypes, while in both the BD and HC groups participants with the Val/Met BDNF genotype had smaller left and right gray matter volumes of the dorsolateral prefrontal cortex.

Increased volumes of the left amygdala were observed in carriers of the $\mathrm{S}$ allele of the 5-HTTLPR gene both in BD and HC groups (Scherk et al., 2009a).

Genetic variations in the CACNA1C genes were not associated with significant structural changes in three VBM studies (Soeiro-de-Souza et al., 2012; Tesli et al., 2013; Wolf et al., 2014), whereas Perrier et al. (2011) found that euthymic BD patients carrying the CACNA1C rs1006737 risk allele had a smaller volume of the left putamen compared HCs.

A significantly increased volume of the left amygdala was associated with the $D G K H$ haplotype (rs994856/rs9525580/rs9525584 GAT) in 30 euthymic patients with type I BD but not in HCs (Kittel-Schneider et al., 2015). The risk genotype (TT) of the NRG1 SNP8NRG221533 was associated with reduced white matter volumes in the fornix, cingulum and para-hippocampal gyrus in a type I BD sample (Cannon et al., 2012). In the same study, BD participants carrying one or two copies of the $H A P_{I C E}$ haplotypes of the NRG1 gene had greater white matter volume than those carrying none in the fornix, caudate and cingulum (Cannon et al., 2012). Papiol et al. (2008) found that a -511C/T SNP (rs16944) of the IL-1 $\beta$ gene was associated with whole-brain and left dlPFC gray matter deficits in a sample of 20 participants with BD in a VBM study. Two studies found that distinct variations of the ANK3 gene were associated with DTI findings (reduced FA) compatible with widespread white matter deficits in several brain regions, such as the forceps minor, the uncinate fasciculus, the anterior cingulate gyrus, the dorsolateral frontal cortex, the left temporoparietal WM, and in posterior dorsomedial WM (Lippard et al., 2016; Ota et al., 2016). Finally, compared to the G allele of the GRIN2 $B$ gene, brain FA values were significantly lower in $\mathrm{BD}$ patients with risk $\mathrm{T}$ allele in left and right frontal regions, left parietal region, left and right occipital regions and the left cingulate gyrus (Kuswanto et al., 2013).

\subsection{2. $f M R I$ studies}

Functional neuroimaging alterations were associated with genetic variations in the CACNA1C, ANK3, DISC1, TNF, DAOA, 5-HTTLPR and NRG1 genes (Table 5).

The most frequent regions with functional alterations significantly associated with genetic variations in BD were: (1) the right anterior CG (ACG), where variation in the ANK3 and TNF genes were associated with greater activation in working memory tasks (ANK3) or Posner task (TNF), whereas the 5-HTTLPR S allele was significantly associated with lower activation during an emotional processing task; (2) the left ACG, where polymorphisms in the TNF gene were associated with increased activation and the 5-HTTLPR S allele with decreased activation during emotional processing tasks; (3) left amygdala, where variation in the CACNA1C and TNF genes were associated with greater activation during emotional processing tasks; (4) left CG, where polymorphisms in DISC1 were associated with lower activation during a verbal fluency task; (5) left para-hippocampal gyrus, where ANK3 polymorphisms were associated with greater activation; and during a working memory 


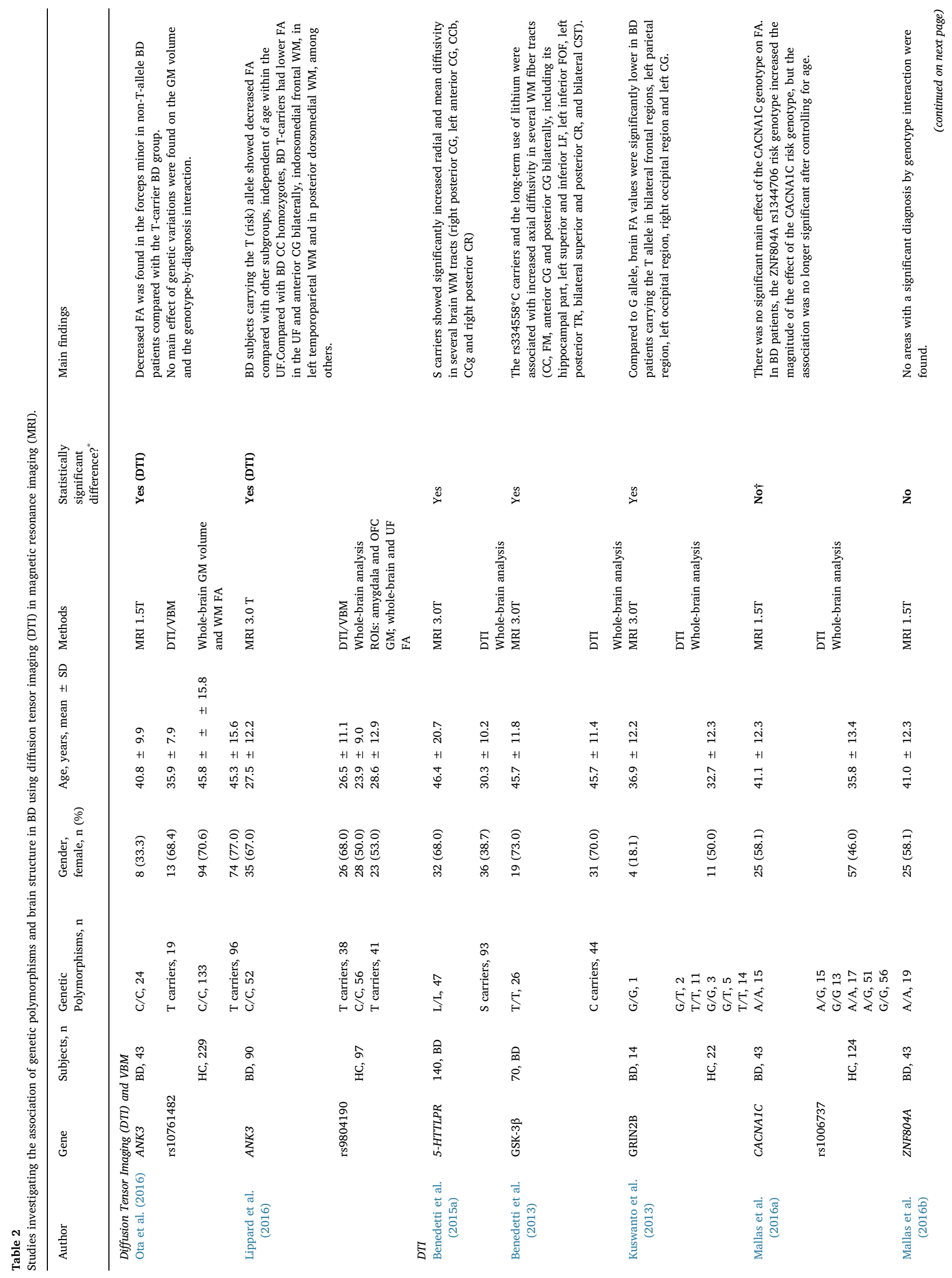


task; and (6) the left vlPFC, where variations in both CACNA1C and 5HTTLPR genes were associated with greater activation during emotional processing tasks.

The fMRI paradigms that were most frequently used across functional neuroimaging studies with statistically significant genetic-imaging findings were emotional faces task ( 8 studies) and the verbal fluency test ( 2 studies). Three studies found associations of the CACNA1C risk allele A with an increase in activation of either left or right amygdala (Jogia et al., 2011; Tesli et al., 2013), and a hypoactivation of the vlPFC (Dima et al., 2013; Jogia et al., 2011), with one study reported both alterations (Jogia et al., 2011) in the emotional faces task. The remaining studies found decreased activation of the vlPFC in association with the ANK3 rs10994336 polymorphism risk allele T (Delvecchio et al., 2015) or a decreased activation of the ventral anterior cingulate gyrus related to the 5HTTLPR S risk allele (Shah et al., 2009). Studies that employed the verbal fluency test were inconsistent regarding both genetic variations and activated ROIs (Mechelli et al., 2012; Mechelli et al., 2008).

\subsubsection{Illustrative brain map of significant replicated gene-neuroimaging findings}

Fig. 2 summarized replicated gene-imaging findings in BD patients in comparison to healthy controls. A difference was considered statistically significant $(p<0.05)$ only if the neuroimaging findings of BD patients carrying the risk allele were different from the HCs or BD subjects not carrying the risk allele (i.e., a gene $\mathrm{x}$ diagnosis interaction). Two fMRI studies found that individuals with BD carrying the A variant of the CACNA1C Rs1006737 polymorphism had decreased activity in the right dorsal ventrolateral prefrontal cortex during the emotional faces paradigm. However, samples across those two investigations appeared to overlap (Dima et al., 2013; Jogia et al., 2011), and thus this association was not regarded as a true replication. Furthermore, two VBM studies found that subjects BD who were carriers of the Met allele of the BDNF Val66Met polymorphism had decreased volumes of the left and right hippocampi (Cao et al., 2016; Chepenik et al., 2009).

\subsection{Methodological considerations}

The minority of included studies enrolled only euthymic BD participants $(\mathrm{k}=10 ; 22.7 \%)$, while the mood status of participants with BD was clearly described in $21(47.7 \%)$ studies. Twenty studies (45.5\%) controlled results for the effects of medication or otherwise included only drug-free BD participants, while most included studies controlled findings for multiple comparisons $(\mathrm{k}=33 ; 75.0 \%)$. A healthy control group was included in $36(81.8 \%)$ studies. The median (IQR) sample sizes for VBM, DTI and fMRI studies were 80 (72-84), 153.5 (87.25-172) and 80.5 (69.5-87.25). A whole-brain analysis was conducted in 15 (34.0\%) studies, while 18 (40.9\%) studies performed only a priori defined ROI-based analyses, and $4(9.1 \%)$ studies carried out both types of analyses. Twenty-eight studies used a $1.5 \mathrm{~T}$ magnetic field, 13 studies used 3.0T, 1 study $4.0 \mathrm{~T}$ and 2 did not specify the magnetic field of the scanner.

\section{Discussion}

The aim of this systematic review was to assess the extant literature reporting 'imaging genetics' findings in BD. We included both structural and functional MRI studies. The most frequently reported genes (at least 2 studies) with statistically significant neuroimaging alterations in BD patients were CACNA1C, ANK3, BDNF, 5-HTTLPR, NRG1 and DAOA. Of those genes, loci close to the CACNA1C and ANK3 genes have reached genome-wide significant associations with $\mathrm{BD}$, and associations were replicated in at least one independent dataset (Goes, 2016). To our knowledge this effort represents the largest evidence-based synthesis to date of this field. 


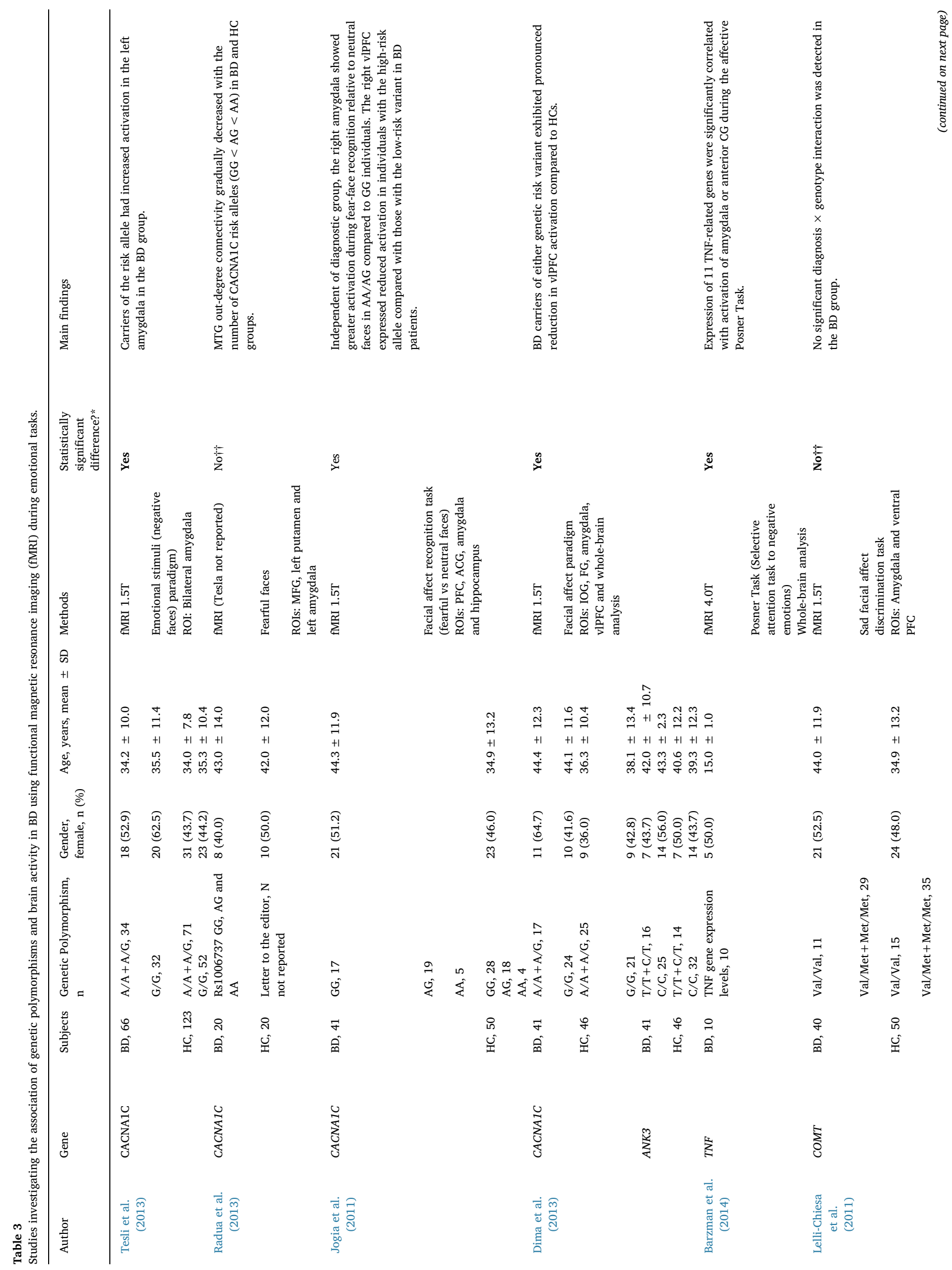




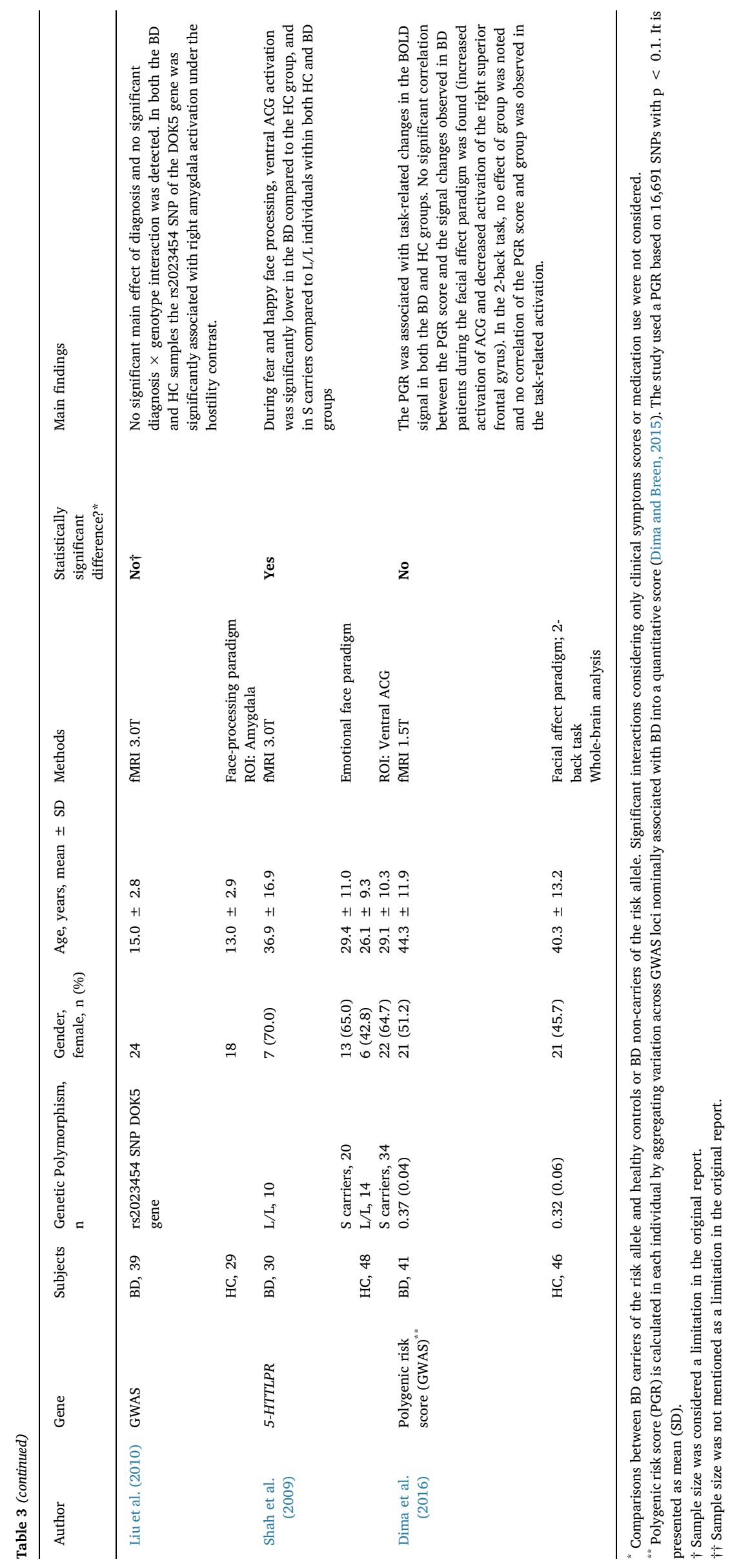




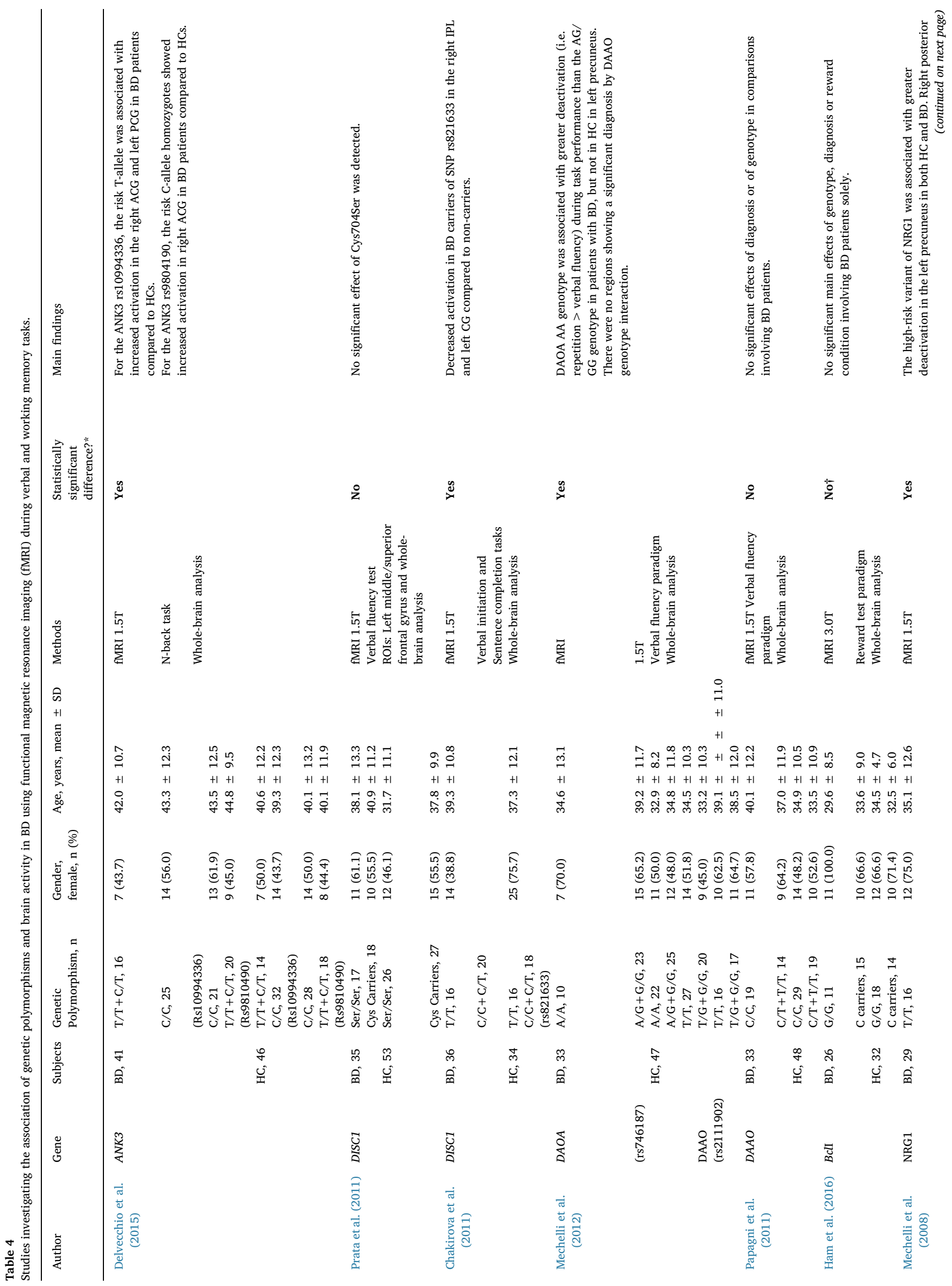


Our findings suggest that the effects of genetic variants on intermediate neuroimaging phenotypes could be independent (i.e., pleiotropic) of effects on the clinical phenotype per se (Gottesman and Gould, 2003), which is consistent with the view that an endophenotypic approach may aid in the search of biological pathways underpinning heterogeneous mental disorders like BD (Miskowiak et al., 2016). The findings reviewed herein may at least partly explain that although at the population level BD is associated with a significant degree of both "cold" and "hot" (i.e., emotion-laden) (Miskowiak and Carvalho, 2014; Roiser et al., 2009) cognitive deficits, recent meta-analyses point to a significant degree of heterogeneity (Bora and Pantelis, 2016; Bortolato et al., 2015; Bourne et al., 2013). Nevertheless, a certain degree of uncertainty lies on the precise pathways which could be influenced by those gene products with relevance to the underlying neurobiology of subsets of individuals with BD. Furthermore, one cannot exclude the possibility that those risk genetic variants are not inherently causal, but instead may be passed in linkage disequilibrium with causative ones. We observed that although several candidate gene studies reported significant associations with structural/functional neuroimaging findings, whilst the few studies that followed a GWAS methodology did not report statistically significant findings (Bakken et al., 2011; Liu et al., 2010; Oertel-Knochel et al., 2015). Evidence indicates that the literature on structural and functional neuroimaging studies could be limited by an excess of significance bias (i.e., there is an excess of statistically significant findings), which may undermine the reproducibility of the field as a whole (Fusar-Poli et al., 2014; Ioannidis et al., 2014). In addition, a selective reporting of outcomes (i.e., only those genes with statistically significant findings are reported) could result in a type I error (Ioannidis et al., 2014). Moreover, sample sizes varied across studies, and due to the few studies available it is difficult to estimate the statistical power of individual studies. This aspect may also undermine the reproducibility of gene-imaging studies as discussed in detail elsewhere (Carter et al., 2016). Therefore, we focused our discussion on candidate genes with at least two statistically significant findings. Furthermore, we contextualized the main findings of our review with data derived from the preclinical and neuropsychological literature.

\subsection{The CACNA1C gene}

The CACNA1C gene encodes the L-type voltage-dependent calcium channel 1C subunit, and at least two GWAS have implicated its rs1006737 SNP as a risk variant associated with BD (Sklar et al., 2008). This association has been consistently replicated since then (Goes, 2016). Notwithstanding Perrier et al. (2011) observed a significantly reduced volume of the left putamen in a sample of $\mathrm{BD}$ patients carrying the rs1006737 SNP risk allele compared to HCs. However, two subsequent VBM studies failed to replicate those findings (Soeiro-de-Souza et al., 2012; Wolf et al., 2014).

Significant within-group differences were observed in BD who were carriers of the risk allele of the CACNA1C gene after recognition of negative/fearful faces (compared to neutral faces) in the facial affect recognition task. For example, carriers of the risk allele had a higher activation of the left amygdala in one study (Tesli et al., 2013), while another study found higher activation of the amygdala bilaterally in the same task (Jogia et al., 2011). Furthermore, two studies found an hyperactivation of the left ventrolateral prefrontal cortex in the same experimental paradigm (Dima et al., 2013; Jogia et al., 2011). Nevertheless, another study did not report significant functional brain abnormalities related to this risk allele in the facial emotion recognition task (Radua et al., 2013). Methodological differences across studies may explain those discrepant findings. For example, Radua et al. (2013) did not explicitly exclude BD participants with co-occurring somatic and mental disorders. Furthermore, there was an overlap in samples included in the studies carried out by Jogia et al. (2011) and Dima et al. (2013). Ou et al. (2015) postulated that the lack of significant differences in neuroimaging studies between participants with BD and 


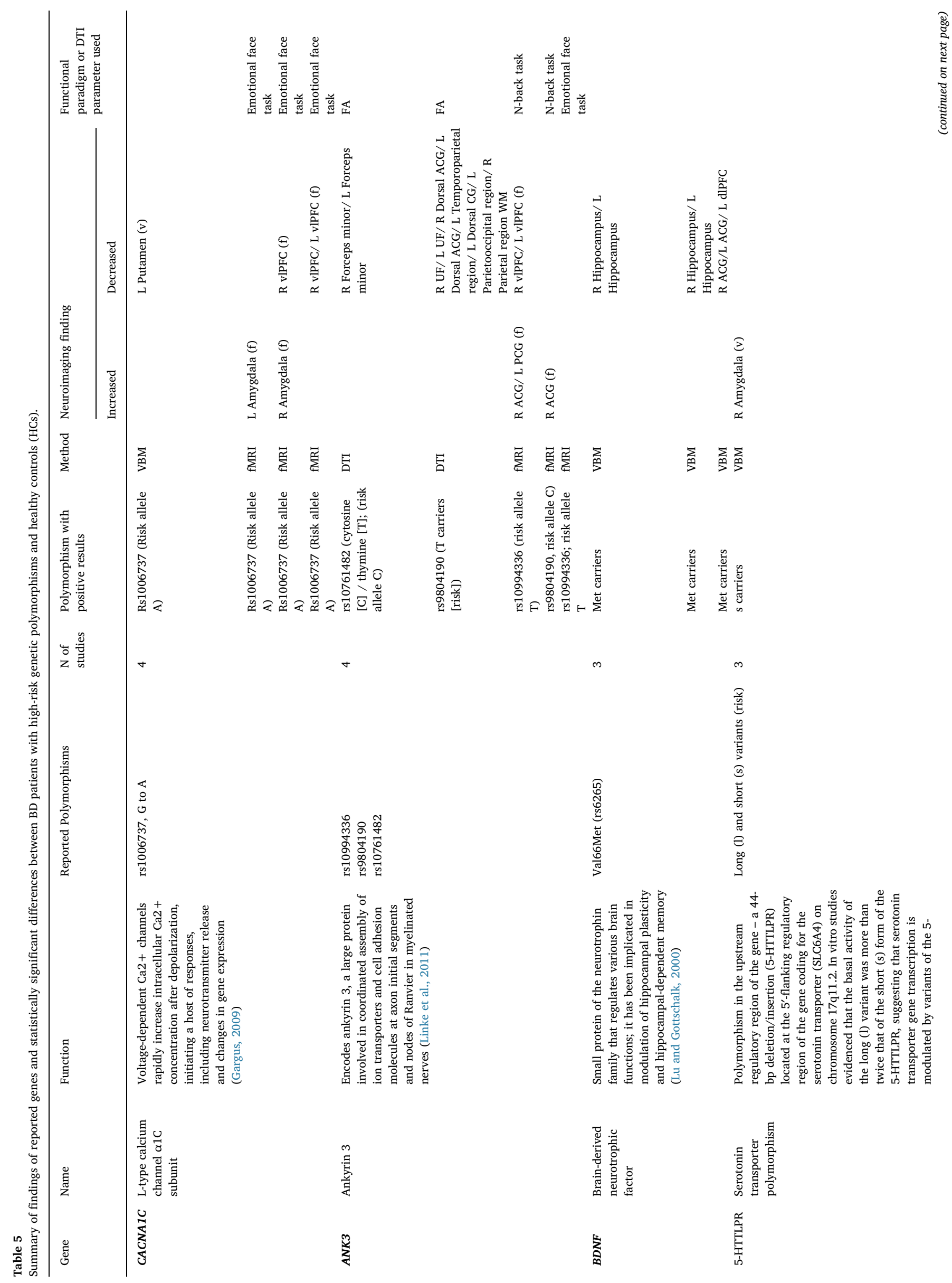




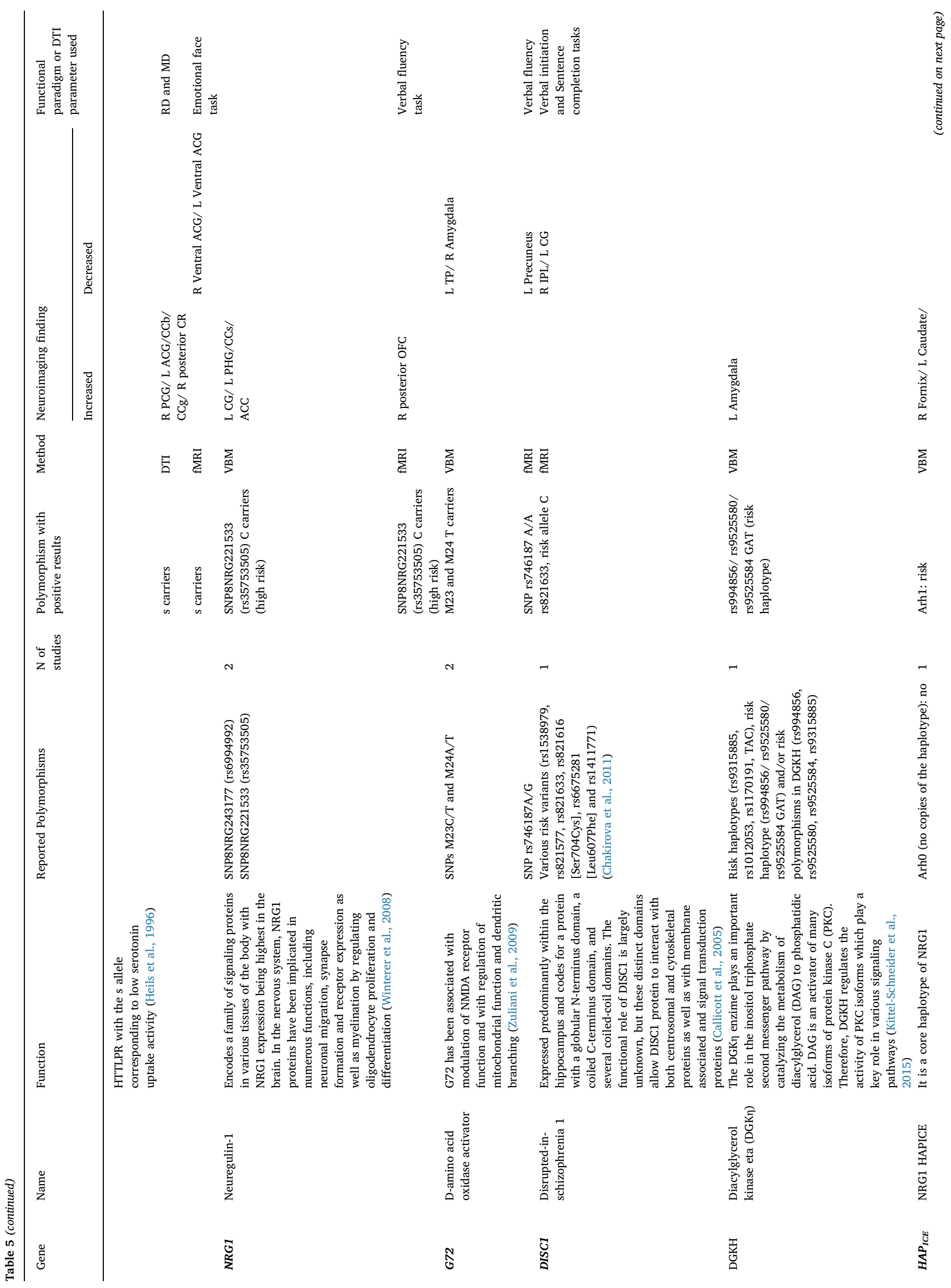




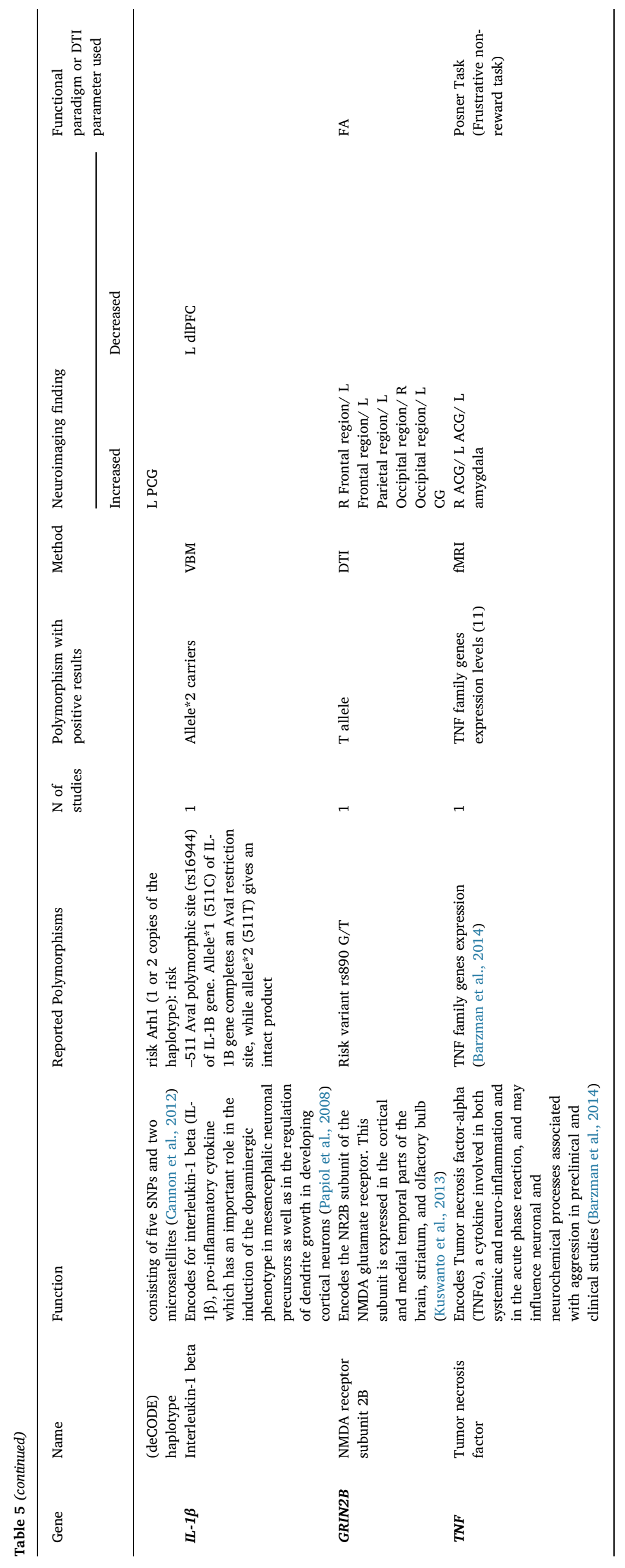




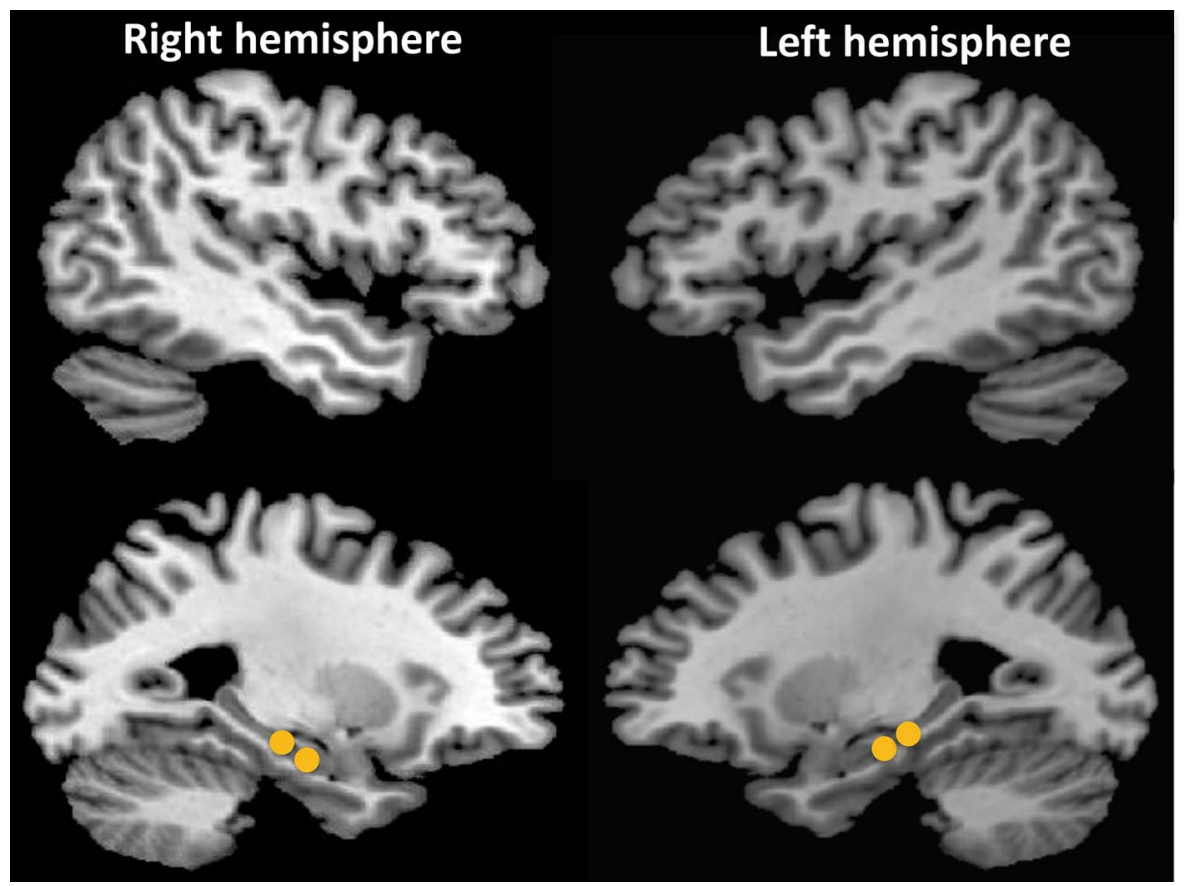

BDNF Val66Met (Met carriers)

Decreased volume in VBM studies

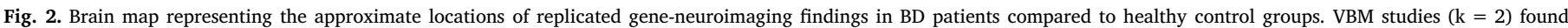

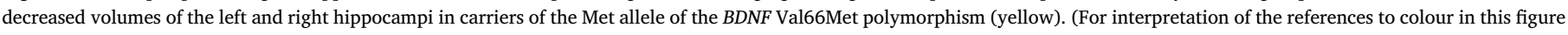
legend, the reader is referred to the web version of this article.)

HCs as a function of the CACNA1C risk allele could be due to differences in the prevalence of cardiovascular risk factors. Therefore, differences in eligibility criteria across studies may at least in part explain contrasting results across studies. Nevertheless, those functional brain abnormalities as a function of the presence of the AA/AG CACNA1C risk alleles are consistent with the neuropsychological literature. Hence although less unanimous than the neuroimaging literature, BD patients who carry those risk alleles may score poorer on speed of processing and digit span tests compared to non-carriers (consistent with a lower efficiency of the left ventrolateral prefrontal cortex). In addition, carriers of the risk allele may display impaired recognition of emotional faces (disgust, sadness, happiness, and anger) [see Ou et al. (2015) for a review].

\subsection{The ANK3 gene}

The ANK3 gene codes for Ankyrin G, a protein which may be involved in the stabilization and localization of ion channels and cell adhesion molecules to nodes of Ranvier and initial segments of axon (Gasser et al., 2012). Furthermore, an elegant preclinical study found a lack of voltage-gated sodium channels in GABAergic parvalbumin interneurons in mice deficient of exon 1b of the ANK3 (Lopez et al., 2016). Consistently, mice exhibited an ANK3 gene dose-dependent phenotype characterized by manic-like behavior, epilepsy, and sudden death (Lopez et al., 2016). In addition, Ankyrin G has been implicated in neurodevelopment, and in the onset of myelination (Ching et al., 1999), and also in the regulation of neurogenesis (Durak et al., 2015; Leussis et al., 2012).

Replicated findings indicate that different risk alleles of the ANK3 gene may impact white matter structure in BD. For example, BD patients who were carriers of the risk allele rs10761482 SNP had decreased FA in the forceps minor (Ota et al., 2016), while BD patients who were carriers of the risk allele of the rs 9804190 had decreased FA in the uncinate fasciculus and the cingulate gyrus bilaterally among other regions compared to CC homozygotes (Lippard et al., 2016). These findings are consistent with a recent meta-analysis of DTI studies in BD which evidences widespread white matter in this illness compared to controls (Nortje et al., 2013). Greater widespread abnormalities in individuals with $\mathrm{BD}$ carrying risk variants of the ANK3 gene also provide support for a putative role of Ankyrin G in myelination. In addition, risk alleles of this gene could lead to accelerated brain aging in BD (Rizzo et al., 2014). Furthermore, the risk C-allele of rs10761482 SNP was significantly associated with worse performance on verbal comprehension, logical memory and processing speed in BD patients in one study (Hori et al., 2014), while another study found that the risk allele of the rs10994336 SNP was associated with reduced sensitivity in target detection and increased errors of commission during sustained attention in both patients with BD and HCs (Ruberto et al., 2011). Altogether, these data suggest that different risk alleles of the ANK3 gene could have a deleterious effect on WM structure in $\mathrm{BD}$, which could be related to neurocognitive deficits. This hypothesis is further supported by a study that found that the risk allele of the rs10994336 SNP was associated with hyperactivation of the right anterior cingulate cortex and left posterior cingulate cortex in patients with BD compared to HCs in the N-back test, which measures executive function (Delvecchio et al., 2015).

\subsection{The BDNF gene}

The brain-derived neurotrophic factor $(B D N F)$ gene is located on chromosome $11 \mathrm{p} 14.1$. The BDNF protein is a member of the neurotrophin superfamily, which supports neuronal survival, neural differentiation during development, and has been implicated in the regulation of activity dependent-synaptic plasticity in mature neurons (Duman and Monteggia, 2006; Hempstead, 2015). This neurotrophin is abundantly expressed in the hippocampus (Duman and Monteggia, 2006). The BDNF rs6265 SNP has been frequently investigated and an alteration at nucleotide 196 (G/A) which produces a Val66Met substitution (Notaras et al., 2015a). This SNP may result in a diminished cellular trafficking and packaging of the mature BDNF protein into the secretory vesicles, thus reducing depolarization-induced release of this neurotrophin (Notaras et al., 2015a). Furthermore, carriers of this risk SNP could produce the Met BDNF prodomain in larger amounts, with may have opposing effects (i.e., a negative impact in 
neuron architecture remodeling) via an activation of the p75 and sortilin-related VPS10 domain containing receptor 2 (SorCS2) receptors (Hempstead, 2015). Consistently, this systematic review found replicated evidence that carriers of the BDNF met allele exhibit smaller hippocampal volumes (Cao et al., 2016; Chepenik et al., 2009). In one study BD carriers of this risk allele presented smaller hippocampal volumes compared to HCs (Cao et al., 2016), whereas in carriers of the Met allele had smaller hippocampus regardless of diagnostic group (i.e., BD or HC) (Chepenik et al., 2009). Zeni et al. (2016) studied a sample of pediatric patients with $\mathrm{BD}$, and found that the Met allele of the BDNF gene had no influence on hippocampal volumes. A potential explanation for this finding is that this SNP could influence hippocampal volume over time as suggested by a previous study (McIntosh et al., 2007). A previous meta-analysis found that neuropsychiatric patients with either the Val/Val genotype or Met-carriers had significantly smaller hippocampal volumes compared to HCs with the same genotypes (Harrisberger et al., 2015). Therefore, it is possible that the Met risk allele could mediate within group differences in BD samples, but not differences between participants with BD and HCs.

A recent meta-analysis suggests that the BDNF Val66Met SNP is not associated with BD (Gonzalez-Castro et al., 2015), although this association could be significant in European populations (Li et al., 2016). This highlights that the effects of the Met allele of the BDNF gene could be more readily demonstrated at the neuroimaging or neuropsychological level than at the diagnostic level. Hence, several studies suggest that individuals with BD carrying the Met allele could have worse cognitive function in several domains including memory (Cao et al., 2016; Rybakowski et al., 2003; Rybakowski et al., 2006; Tramontina et al., 2009), although this association has not been unanimously demonstrated across studies (Rolstad et al., 2016; Rosa et al., 2014). These discrepancies may be related to the influence of concomitant medication (Grande et al., 2014). Furthermore, the involvement of BDNF in the pathophysiology of BD is supported by a recent meta-analysis which found that peripheral levels of this protein could be a biomarker of illness activity (Fernandes et al., 2015). Finally, preclinical evidence points to a role for BDNF in BD (de Souza Gomes et al., 2015; Macedo et al., 2012).

\subsection{The 5-HTTLPR gene}

A functional polymorphism (5-HTTLPR) in the promoter of serotonin transporter gene (SLC6A4) has been described in 1996 (Lesch et al., 1996). Since then, the impact of this polymorphism in a range of mental disorders and intermediate phenotypes have been a focus of substantial research efforts [see Jonassen and Landro (2014) for a review]. In addition, evidence suggests that methylation of the serotonin transporter gene may provide an epigenetic marker of exposure to life adversities (Provenzi et al., 2016). Notwithstanding the 5-HTTLPR polymorphism does not seem to affect the methylation status of the SLC6A4 gene, preliminary evidence suggests a possible interaction of methylation status and the short (S) allele in the development of stressrelated mood disorders (Olsson et al., 2010).

Benedetti et al. (2014) observed that the S allele of the 5-HTTLPR mediated the effect of early life stress on gray matter volumes in the right prefrontal cortex in a sample with BD. Furthermore, the $\mathrm{S}$ allele was also associated with higher right amygdala volumes in both patients with BD and HCs. Notwithstanding a previous meta-analysis suggests that the $S$ allele could lead to amygdala hyperactivation in emotional paradigms (Murphy et al., 2013), our systematic review did not find a study to replicate this finding in BD. Nevertheless, one study found that $S$ carriers had lower ventral anterior cingulate cortex activation compared to $\mathrm{L} / \mathrm{L}$ participants during processing of happy and fear faces; this effect was evident in both the HC and BD groups (Shah et al., 2009). Clearly effects of the 'S' 5-HTTLPR on intermediate phenotypes in BD deserve further investigation.

\subsection{The NRG1 gene}

Evidence indicates that neuregulin 1 and its cognate receptor ErB4 play significant roles in the regulation of synaptic transmission, myelin formation, and neuronal and glial cell survival (Mei and Nave, 2014). Although variations in NRG1 gene were initially associated with schizophrenia [see Mostaid et al. (2016) for a review], subsequent studies pointed to a possible association with BD (Cao et al., 2014; Georgieva et al., 2008; Green et al., 2005; Gutierrez-Fernandez et al., 2014), notwithstanding this findings has not been supported thus far by GWAS (Goes, 2016). In keeping with this view, a study found aberrant cleavage of the neuregulin 1 in the post mortem hippocampus of individuals with BD (Marballi et al., 2012). We found evidence that a risk NRG1 SNP (SNP8NRG221533) and its HAP ICE haplotype was associated with greater white matter in the fornix, cingulum, parahippocampal gyrus, and the corpus callosum (Cannon et al., 2012). In addition, a functional neuroimaging study found that individuals with BD carrying the high-risk SNP (rs35753505) of the NRG1 gene displayed hyperactivation of the right posterior orbitofrontal cortex compared to non-carriers (Mechelli et al., 2012). Clearly the impact of high-risk variants of the NRG1 gene on structural and functional brain abnormalities in individuals with BD require further study.

\subsection{Limitations}

The findings of this systematic review should be interpreted within its limitations. First, the methodological quality of included studies varied. For example, the mood state of participants with BD varied across studies. In addition, some studies did not include a HC group, while few studies did not control results for multiple comparisons. Second, several confounding variables should be considered (e.g., differences in length of illness, number of previous affective episodes, and exposure to mood stabilizing medications). For example, it has been suggested that hippocampal volumes in BD may vary as a function of the number of affective episodes in a subset of patients with neuroprogressive forms of the illness (Cao et al., 2017; Lim et al., 2013). Furthermore, the large majority of studies included in this systematic review enrolled adult samples. For example, a meta-analysis indicates that hyperactivation of the amygdala across emotional face recognition fMRI studies is more evident in BD-youths than among BDadults (Wegbreit et al., 2014). Third, although our findings indicate that the effects of genetic variants in the risk of BD may be more readily reflected as at the brain structure/function level than in the disease per se, this notion has been challenged by some experts. For example, Flint and Munafo (2007) provides meta-analytic evidence that the effect sizes of illness-related genetic variants on intermediate phenotypes may not necessarily be larger than the ones observed for the illness phenotype. Fourth, we included structural and functional MRI studies, but not other imaging tools (e.g., positron emission tomography). Fifth, although we found promising replicated findings, several significant associations deserve replication. For example, converging evidence from both preclinical and GWAS studies have implicated ANK3 as a putative risk gene for $\mathrm{BD}$, while recent gene imaging studies offered promising initial results (Lippard et al., 2016). In addition, the reproducibility of this field deserves careful examination (Carter et al., 2016). Sixth, the use of pre-defined ROI-based analyses could bias some of the converging findings of this review. For example, the study by Chepenik et al. (2009) in which the Met allele of the BDNF Val66Met polymorphism was associated with bilateral hippocampi reduction in individuals with $\mathrm{BD}$ restricted their analyses to this brain structure.

\subsection{Implications}

This systematic review open several research implications. It has been increasingly recognized that neurobiological abnormalities span 
conventional diagnostic categories in psychiatry. This fact motivated the NIMH to launch the Research Domain Criteria (RDoC) initiative (Cuthbert and Insel, 2013), with an attempt to provide a complimentary research classification system for mental disorders built upon dimensions of neurobiology and observable behavior, and moving towards precision psychiatry (Fernandes et al., 2017; Vieta, 2015). Consistent with this assumption several genetic risk variants seem to overlap across major mental disorders (Gatt et al., 2015). Furthermore, a recent study investigated a large panel of brain-based biomarkers and included participants across the psychotic spectrum (schizophrenia, schizoaffective disorder, and BD), and found three distinct psychotic biotypes that did not respect diagnostic categories (Clementz et al., 2016). Consistently, the only replicated finding observed in this review is also apparent in similar studies involving schizophrenia samples. For example, the Val66Met BDNF polymorphism has also been associated with reduced hippocampi volume in schizophrenia (Notaras et al., 2015b), while a recent systematic review found that several putative risk genes for both $\mathrm{BD}$ and schizophrenia may influence brain structure and function in healthy control samples (Gurung and Prata, 2015). Therefore, future efforts to replicate the findings of this systematic review could include participants with different diagnostic categories, and a better control of potential confounding variables (e.g. concomitant medication and substance use. In addition, the a priori publication of research protocols in the field of 'imaging genetics' could improve its reproducibility and reduce the risk of selective outcome reporting (Carter et al., 2016).

\section{Conclusion}

This review synthesis indicates that the 'gene-imaging' research paradigm may aid in the identification of intermediate phenotypes, and therefore could provide more consistent biological mechanistic insights for BD. Variants in the CACNA1C, ANK3, and BDNF genes yielded the most consistent findings thus far, by applying neuroimaging paradigms to GWAS-emerging candidate genes. Future research efforts should include samples with different diagnostic categories, and the development of collaborative consortia with a priori published protocols could enhance the impact of future efforts. However, highly robust findings are unlikely if the only source of candidate genes are GWAS and gene polymorphisms, and neuroimaging studies are particularly difficult in bipolar patients because of the influence of complex medication regimes.

\section{Role of funding source}

This study received no funding.

\section{Contributors}

LPP, CAK and AFC designed the protocol and searched the literature. LPP and BPF screened the studies and extracted the data. LPP, CAK and AFC analyzed the data. LPP, CAK, RTS and AFC wrote the first draft of the manuscript. MS, BPF, MF, RMV, KWM, EV, NV and BS contributed to the interpretation and discussion of the findings, and to the writing of the manuscript. All authors have read and approved the final version of this manuscript for submission. All authors have participated sufficiently in the work to take responsibility for its content.

\section{Conflict of interest}

The authors declare no conflicts of interest that could influence this work.

\section{Acknowledgements}

CAK is supported by a postdoctoral fellowship from Coordenação de Aperfeiçoamento de Pessoal de Nível Superior (CAPES, Brazil). The Lundbeckfonden and the Weimann Foundation provide support for half of KWM's salary as senior research psychologist at Copenhagen Affective Disorders Research Centre and University of Copenhagen, Denmark, which enables her to do fulltime research until 2020. AFC is the recipient of a research fellowship award from the Conselho de Desenvolvimento Científico e Tecnológico (CNPq; Brazil).

\section{Appendix A. Supplementary data}

Supplementary data associated with this article can be found, in the online version, at http://dx.doi.org/10.1016/j.neubiorev.2017.05.002.

\section{References}

Bakken, T.E., Bloss, C.S., Roddey, J., Joyner, A.H., Rimol, L.M., Djurovic, S., Melle, I., Sundet, K., Agartz, I., Andreassen, O.A., Dale, A.M., Schork, N.J., 2011. Association of genetic variants on $15 q 12$ with cortical thickness and cognition in schizophrenia. Arch. Gen. Psychiatry 68, 781-790.

Barzman, D., Eliassen, J., McNamara, R., Abonia, P., Mossman, D., Durling, M., Adler, C. DelBello, M., Lin, P.I., 2014. Correlations of inflammatory gene pathways, corticolimbic functional activities, and aggression in pediatric bipolar disorder: a preliminary study. Psychiatry Res. 224, 107-111.

Benedetti, F., Bollettini, I., Barberi, I., Radaelli, D., Poletti, S., Locatelli, C., Pirovano, A., Lorenzi, C., Falini, A., Colombo, C., Smeraldi, E., 2013. Lithium and GSK3-beta promoter gene variants influence white matter microstructure in bipolar disorder. Neuropsychopharmacology 38, 313-327.

Benedetti, F., Riccaboni, R., Poletti, S., Radaelli, D., Locatelli, C., Lorenzi, C., Pirovano, A., Smeraldi, E., Colombo, C., 2014. The serotonin transporter genotype modulates the relationship between early stress and adult suicidality in bipolar disorder. Bipolar Disord. 16, 857-866.

Benedetti, F., Bollettini, I., Poletti, S., Locatelli, C., Lorenzi, C., Pirovano, A., Smeraldi, E., Colombo, C., 2015a. White matter microstructure in bipolar disorder is influenced by the serotonin transporter gene polymorphism 5-HTTLPR. Genes Brain Behav. 14, 238-250.

Benedetti, F., Poletti, S., Radaelli, D., Locatelli, C., Pirovano, A., Lorenzi, C., Vai, B., Bollettini, I., Falini, A., Smeraldi, E., Colombo, C., 2015b. Lithium and GSK-3beta promoter gene variants influence cortical gray matter volumes in bipolar disorder. Psychopharmacology (Berl.) 232, 1325-1336.

Bergmann, O., Haukvik, U.K., Brown, A.A., Rimol, L.M., Hartberg, C.B., Athanasiu, L. Melle, I., Djurovic, S., Andreassen, O.A., Dale, A.M., Agartz, I., 2013. ZNF804A and cortical thickness in schizophrenia and bipolar disorder. Psychiatry Res. Neuroimag. 212, 154-157.

Bigos, K.L., Weinberger, D.R., 2010. Imaging genetics-days of future past. Neuroimage 53, 804-809.

Bora, E., Pantelis, C., 2016. Social cognition in schizophrenia in comparison to bipolar disorder: a meta-analysis. Schizophr. Res. 175, 72-78.

Bortolato, B., Miskowiak, K.W., Kohler, C.A., Vieta, E., Carvalho, A.F., 2015. Cognitive dysfunction in bipolar disorder and schizophrenia: a systematic review of metaanalyses. Neuropsychiatr. Dis. Treatment 11, 3111-3125.

Bourne, C., Aydemir, O., Balanza-Martinez, V., Bora, E., Brissos, S., Cavanagh, J.T., Clark, L., Cubukcuoglu, Z., Dias, V.V., Dittmann, S., Ferrier, I.N., Fleck, D.E., Frangou, S., Gallagher, P., Jones, L., Kieseppa, T., Martinez-Aran, A., Melle, I., Moore, P.B., Mur, M., Pfennig, A., Raust, A., Senturk, V., Simonsen, C., Smith, D.J., Bio, D.S., Soeiro-deSouza, M.G., Stoddart, S.D., Sundet, K., Szoke, A., Thompson, J.M., Torrent, C., Zalla, T., Craddock, N., Andreassen, O.A., Leboyer, M., Vieta, E., Bauer, M., Worhunsky, P.D., Tzagarakis, C., Rogers, R.D., Geddes, J.R., Goodwin, G.M., 2013. Neuropsychological testing of cognitive impairment in euthymic bipolar disorder: an individual patient data meta-analysis. Acta Psychiatr. Scand. 128, 149-162.

Callicott, J.H., Straub, R.E., Pezawas, L., Egan, M.F., Mattay, V.S., Hariri, A.R., Verchinski, B.A., Meyer-Lindenberg, A., Balkissoon, R., Kolachana, B., Goldberg, T.E., Weinberger, D.R., 2005. Variation in DISC1 affects hippocampal structure and function and increases risk for schizophrenia. Proc. Natl. Acad. Sci. U. S. A. 102, 8627-8632.

Cannon, D.M., Walshe, M., Dempster, E., Collier, D.A., Marshall, N., Bramon, E., Murray, R.M., McDonald, C., 2012. The association of white matter volume in psychotic disorders with genotypic variation in NRG1, MOG and CNP: a voxel-based analysis in affected individuals and their unaffected relatives. Transl. Psychiatry 2, e167.

Cao, L., Deng, W., Guan, L., Yang, Z., Lin, Y., Ma, X., Li, X., Liu, Y., Ye, B., Lao, G., Chen, Y., Liang, H., Wu, Y., Ou, Y., Huang, W., Liu, W., Wang, Q., Wang, Y., Zhao, L., Li, T., Hu, X., 2014. Association of the 3 ' region of the neuregulin 1 gene with bipolar I disorder in the Chinese Han population. J. Affect. Disord. 162, 81-88.

Cao, B., Bauer, I.E., Sharma, A.N., Mwangi, B., Frazier, T., Lavagnino, L., Zunta-Soares, G.B., Walss-Bass, C., Glahn, D.C., Kapczinski, F., Nielsen, D.A., Soares, J.C., 2016. Reduced hippocampus volume and memory performance in bipolar disorder patients carrying the BDNF val66met met allele. J. Affect. Disord. 198, 198-205.

Cao, B., Passos, I.C., Mwangi, B., Amaral-Silva, H., Tannous, J., 2017. Hippocampal 
subfield volumes in mood disorders.

Carter, C.S., Bearden, C.E., Bullmore, E.T., Geschwind, D.H., Glahn, D.C., Gur, R.E., Meyer-Lindenberg, A., Weinberger, D.R., 2016. Enhancing the informativeness an replicability of imaging genomics studies. Biol. Psychiatry. http://dx.doi.org/10. 1016/j.biopsych.2016.08.019.

Chakirova, G., Whalley, H.C., Thomson, P.A., Hennah, W., Moorhead, T.W., Welch, K.A., Giles, S., Hall, J., Johnstone, E.C., Lawrie, S.M., Porteous, D.J., Brown, V.J., McIntosh, A.M., 2011. The effects of DISC1 risk variants on brain activation in controls, patients with bipolar disorder and patients with schizophrenia. Psychiatry Res. 192, 20-28.

Chepenik, L.G., Fredericks, C., Papademetris, X., Spencer, L., Lacadie, C., Wang, F., Pittman, B., Duncan, J.S., Staib, L.H., Duman, R.S., Gelernter, J., Blumberg, H.P., 2009. Effects of the brain-derived neurotrophic growth factor val66met variation on hippocampus morphology in bipolar disorder. Neuropsychopharmacology 34, 944-951.

Ching, W., Zanazzi, G., Levinson, S.R., Salzer, J.L., 1999. Clustering of neuronal sodium channels requires contact with myelinating Schwann cells. J. Neurocytol. 28, 295-301.

Clementz, B.A., Sweeney, J.A., Hamm, J.P., Ivleva, E.I., Ethridge, L.E., Pearlson, G.D., Keshavan, M.S., Tamminga, C.A., 2016. Identification of distinct psychosis biotypes using brain-based biomarkers. Am. J. Psychiatry 173, 373-384.

Craddock, N., Sklar, P., 2013. Genetics of bipolar disorder. Lancet (London, England) 381, 1654-1662.

Cuthbert, B.N., Insel, T.R., 2013. Toward the future of psychiatric diagnosis: the seven pillars of RDoC. BMC Med. 11, 126.

Delvecchio, G., Dima, D., Frangou, S., 2015. The effect of ANK3 bipolar-risk polymorphisms on the working memory circuitry differs between loci and according to risk-status for bipolar disorder. Am. J. Med. Genet. B: Neuropsych. Genet. 168, 188-196.

de Souza Gomes, J.A., de Souza, G.C., Berk, M., Cavalcante, L.M., de Sousa, F.C., Budni, J., de Lucena, D.F., Quevedo, J., Carvalho, A.F., Macedo, D., 2015. Antimanic-like activity of candesartan in mice: possible involvement of antioxidant, antiinflammatory and neurotrophic mechanisms. Eur. Neuropsychopharmacol. 25, 2086-2097.

Dima, D., Breen, G., 2015. Polygenic risk scores in imaging genetics: usefulness and applications. J. Psychopharmacol. (Oxford, England) 29, 867-871.

Dima, D., Jogia, J., Collier, D., Vassos, E., Burdick, K.E., Frangou, S., 2013. Independent modulation of engagement and connectivity of the facial network during affect processing by CACNA1C and ANK3 risk genes for bipolar disorder. JAMA Psychiatry $70,1303-1311$

Dima, D., de Jong, S., Breen, G., Frangou, S., 2016. The polygenic risk for bipolar disorder influences brain regional function relating to visual and default state processing of emotional information. Neuroimage Clin. 12, 838-844.

Duman, R.S., Monteggia, L.M., 2006. A neurotrophic model for stress-related mood disorders. Biol. Psychiatry 59, 1116-1127.

Durak, O., de Anda, F.C., Singh, K.K., Leussis, M.P., Petryshen, T.L., Sklar, P., Tsai, L.H., 2015. Ankyrin-G regulates neurogenesis and Wnt signaling by altering the subcellular localization of beta-catenin. Mol. Psychiatry 20, 388-397.

Fernandes, B.S., Molendijk, M.L., Kohler, C.A., Soares, J.C., Leite, C.M., Machado-Vieira, R., Ribeiro, T.L., Silva, J.C., Sales, P.M., Quevedo, J., Oertel-Knochel, V., Vieta, E., Gonzalez-Pinto, A., Berk, M., Carvalho, A.F., 2015. Peripheral brain-derived neurotrophic factor (BDNF) as a biomarker in bipolar disorder: a meta-analysis of 52 studies. BMC Med. 13, 289.

Fernandes, B.S., Williams, L.M., Steiner, J., Leboyer, M., Carvalho, A.F., Berk, M., 2017. The new field of 'precision psychiatry'. BMC Med. 15, 80.

Flint, J., Munafo, M.R., 2007. The endophenotype concept in psychiatric genetics. Psychol. Med. 37, 163-180.

Fusar-Poli, P., Howes, O., Bechdolf, A., Borgwardt, S., 2012. Mapping vulnerability to bipolar disorder: a systematic review and meta-analysis of neuroimaging studies. J. Psychiatry Neurosci. 37, 170-184.

Fusar-Poli, P., Radua, J., Frascarelli, M., Mechelli, A., Borgwardt, S., Di Fabio, F., Biondi, M., Ioannidis, J.P., David, S.P., 2014. Evidence of reporting biases in voxel-based morphometry (VBM) studies of psychiatric and neurological disorders. Hum. Brain Mapp. 35, 3052-3065.

Gargus, J.J., 2009. Genetic calcium signaling abnormalities in the central nervous system: seizures, migraine, and autism. Ann. N. Y. Acad. Sci. 1151, 133-156.

Gasser, A., Ho, T.S., Cheng, X., Chang, K.J., Waxman, S.G., Rasband, M.N., Dib-Hajj, S.D., 2012. An ankyrinG-binding motif is necessary and sufficient for targeting Nav1.6 sodium channels to axon initial segments and nodes of Ranvier. J. Neurosci. 32, $7232-7243$.

Gatt, J.M., Burton, K.L., Williams, L.M., Schofield, P.R., 2015. Specific and common genes implicated across major mental disorders: a review of meta-analysis studies. J. Psychiatr. Res. 60, 1-13.

Georgieva, L., Dimitrova, A., Ivanov, D., Nikolov, I., Williams, N.M., Grozeva, D., Zaharieva, I., Toncheva, D., Owen, M.J., Kirov, G., O'Donovan, M.C., 2008. Support for neuregulin 1 as a susceptibility gene for bipolar disorder and schizophrenia. Biol. Psychiatry 64, 419-427.

Goes, F.S., 2016. Genetics of bipolar disorder: recent update and future directions. Psychiatric Clin. N. Am. 39, 139-155.

Gonzalez-Castro, T.B., Nicolini, H., Lanzagorta, N., Lopez-Narvaez, L., Genis, A., Pool Garcia, S., Tovilla-Zarate, C.A., 2015. The role of brain-derived neurotrophic factor (BDNF) Val66Met genetic polymorphism in bipolar disorder: a case-control study, comorbidities, and meta-analysis of 16,786 subjects. Bipolar Disord. 17, 27-38.

Gottesman, I.I., Gould, T.D., 2003. The endophenotype concept in psychiatry: etymology and strategic intentions. Am. J. Psychiatry 160, 636-645.

Grande, I., Magalhaes, P.V., Chendo, I., Stertz, L., Fries, G.R., Cereser, K.M., Cunha, A.B.,
Goi, P., Kunz, M., Udina, M., Martin-Santos, R., Frey, B.N., Vieta, E., Kapczinski, F., 2014. Val66Met polymorphism and serum brain-derived neurotrophic factor in bipolar disorder: an open-label trial. Acta Psychiatr. Scand. 129, 393-400.

Grande, I., Berk, M., Birmaher, B., Vieta, E., 2016. Bipolar disorder. Lancet (London, England) 387, 1561-1572.

Green, E.K., Raybould, R., Macgregor, S., Gordon-Smith, K., Heron, J., Hyde, S., Grozeva, D., Hamshere, M., Williams, N., Owen, M.J., O'Donovan, M.C., Jones, L., Jones, I, Kirov, G., Craddock, N., 2005. Operation of the schizophrenia susceptibility gene, neuregulin 1 , across traditional diagnostic boundaries to increase risk for bipolar disorder. Arch. Gen. Psychiatry 62, 642-648.

Green, E.K., Hamshere, M., Forty, L., Gordon-Smith, K., Fraser, C., Russell, E., Grozeva, D., Kirov, G., Holmans, P., Moran, J.L., Purcell, S., Sklar, P., Owen, M.J., O'Donovan, M.C., Jones, L., Jones, I.R., Craddock, N., 2013. Replication of bipolar disorder susceptibility alleles and identification of two novel genome-wide significant associations in a new bipolar disorder case-control sample. Mol. Psychiatry 18, 1302-1307.

Group, P.G.C.B.D.W., 2011. Large-scale genome-wide association analysis of bipolar disorder identifies a new susceptibility locus near ODZ4. Nat. Genet. 43, 977-983.

Gurung, R., Prata, D.P., 2015. What is the impact of genome-wide supported risk variants for schizophrenia and bipolar disorder on brain structure and function: a systematic review. Psychol. Med. 45, 2461-2480.

Gutierrez-Fernandez, A., Palomino, A., Gonzalez-Pinto, A., Ugarte, A., Hernanz, M., Mendibil, B., Etxebeste, M., Pacheco, L., Gonzalez-Garcia, G., Matute, C., 2014. Novel association of Neuregulin 1 gene with bipolar disorder but not with schizophrenia. Schizophr. Res. 159, 552-553.

Ham, B.J., Greenberg, T., Chase, H.W., Phillips, M.L., 2016. Impact of the glucocorticoid receptor Bcl i polymorphism on reward expectancy and prediction error related ventral striatal reactivity in depressed and healthy individuals. J. Psychopharmacol. (Oxf.) 30, 48-55.

Harrisberger, F., Smieskova, R., Schmidt, A., Lenz, C., Walter, A., Wittfeld, K., Grabe, H.J., Lang, U.E., Fusar-Poli, P., Borgwardt, S., 2015. BDNF Val66Met polymorphism and hippocampal volume in neuropsychiatric disorders: a systematic review and metaanalysis. Neurosci. Biobehav. Rev. 55, 107-118.

Hashimoto, R., Ohi, K., Yamamori, H., Yasuda, Y., Fujimoto, M., Umeda-Yano, S., Watanabe, Y., Fukunaga, M., Takeda, M., 2015. Imaging genetics and psychiatric disorders. Curr. Mol. Med. 15, 168-175.

Hasler, G., Wolf, A., 2015. Toward stratified treatments for bipolar disorders. Eur. Neuropsychopharmacol. 25, 283-294.

Hayes, J.F., Miles, J., Walters, K., King, M., Osborn, D.P., 2015. A systematic review and meta-analysis of premature mortality in bipolar affective disorder. Acta Psychiatr. Scand. 131, 417-425.

Heils, A., Teufel, A., Petri, S., Stober, G., Riederer, P., Bengel, D., Lesch, K.P., 1996. Allelic variation of human serotonin transporter gene expression. J. Neurochem. 66, 2621-2624.

Hempstead, B.L., 2015. Brain-Derived neurotrophic factor: three ligands, many actions. Trans. Am. Clin. Climatol, Assoc, 126, 9-19.

Hori, H., Yamamoto, N., Teraishi, T., Ota, M., Fujii, T., Sasayama, D., Matsuo, J., Kinoshita, Y., Hattori, K., Nagashima, A., Ishida, I., Koga, N., Higuchi, T., Kunugi, H., 2014. Cognitive effects of the ANK3 risk variants in patients with bipolar disorder and healthy individuals. J. Affect. Disord. 158, 90-96.

Hou, L., Bergen, S.E., Akula, N., Song, J., Hultman, C.M., Landen, M., Adli, M., Alda, M., Ardau, R., Arias, B., Aubry, J.M., Backlund, L., Badner, J.A., Barrett, T.B., Bauer, M., Baune, B.T., Bellivier, F., Benabarre, A., Bengesser, S., Berrettini, W.H., Bhattacharjee, A.K., Biernacka, J.M., Birner, A., Bloss, C.S., Brichant-Petitjean, C., Bui, E.T., Byerley, W., Cervantes, P., Chillotti, C., Cichon, S., Colom, F., Coryell, W., Craig, D.W., Cruceanu, C., Czerski, P.M., Davis, T., Dayer, A., Degenhardt, F., Del Zompo, M., DePaulo, J.R., Edenberg, H.J., Etain, B., Falkai, P., Foroud, T., Forstner, A.J., Frisen, L., Frye, M.A., Fullerton, J.M., Gard, S., Garnham, J.S., Gershon, E.S., Goes, F.S., Greenwood, T.A., Grigoroiu-Serbanescu, M., Hauser, J., Heilbronner, U., Heilmann-Heimbach, S., Herms, S., Hipolito, M., Hitturlingappa, S., Hoffmann, P., Hofmann, A., Jamain, S., Jimenez, E., Kahn, J.P., Kassem, L., Kelsoe, J.R., KittelSchneider, S., Kliwicki, S., Koller, D.L., Konig, B., Lackner, N., Laje, G., Lang, M., Lavebratt, C., Lawson, W.B., Leboyer, M., Leckband, S.G., Liu, C., Maaser, A., Mahon, P.B., Maier, W., Maj, M., Manchia, M., Martinsson, L., McCarthy, M.J., McElroy, S.L., McInnis, M.G., McKinney, R., Mitchell, P.B., Mitjans, M., Mondimore, F.M., Monteleone, P., Muhleisen, T.W., Nievergelt, C.M., Nothen, M.M., Novak, T., Nurnberger Jr., J.I., Nwulia, E.A., Osby, U., et al., 2016. Genome-wide association study of 40,000 individuals identifies two novel loci associated with bipolar disorder. Hum. Mol. Genet. 25, 3383-3394.

Ioannidis, J.P., Munafo, M.R., Fusar-Poli, P., Nosek, B.A., David, S.P., 2014. Publication and other reporting biases in cognitive sciences: detection, prevalence, and prevention. Trends Cogn. Sci. 18, 235-241.

Ivleva, E.I., Morris, D.W., Moates, A.F., Suppes, T., Thaker, G.K., Tamminga, C.A., 2010. Genetics and intermediate phenotypes of the schizophrenia-bipolar disorder boundary. Neurosci. Biobehav. Rev. 34, 897-921.

Jogia, J., Ruberto, G., Lelli-Chiesa, G., Vassos, E., Maieru, M., Tatarelli, R., Girardi, P., Collier, D., Frangou, S., 2011. The impact of the CACNA1C gene polymorphism on frontolimbic function in bipolar disorder. Mol. Psychiatry 16, 1070-1071.

Jonassen, R., Landro, N.I., 2014. Serotonin transporter polymorphisms (5-HTTLPR) in emotion processing: implications from current neurobiology. Prog. Neurobiol. 117, $41-53$.

Kempton, M.J., Salvador, Z., Munafo, M.R., Geddes, J.R., Simmons, A., Frangou, S., Williams, S.C., 2011. Structural neuroimaging studies in major depressive disorder: meta-analysis and comparison with bipolar disorder. Arch. Gen. Psychiatry 68, 675-690.

Kerner, B., 2014. Genetics of bipolar disorder. Appl. Clin. Genet. 7, 33-42. 
Kittel-Schneider, S., Wobrock, T., Scherk, H., Schneider-Axmann, T., Trost, S., Zilles, D., Wolf, C., Schmitt, A., Malchow, B., Hasan, A., Backens, M., Reith, W., Falkai, P., Gruber, O., Reif, A., 2015. Influence of DGKH variants on amygdala volume in patients with bipolar affective disorder and schizophrenia. Eur. Arch. Psychiatry Clin. Neurosci. 265, 127-136.

Kupferschmidt, D.A., Zakzanis, K.K., 2011. Toward a functional neuroanatomical signature of bipolar disorder: quantitative evidence from the neuroimaging literature. Psychiatry Res. 193, 71-79.

Kurnianingsih, Y.A., Kuswanto, C.N., McIntyre, R.S., Qiu, A., Ho, B.C., Sim, K., 2011 Neurocognitive-genetic and neuroimaging-genetic research paradigms in schizophrenia and bipolar disorder. J. Neural. Transm. (Vienna) 118, 1621-1639.

Kuswanto, C.N., Sum, M.Y., Thng, C.R., Zhang, Y.B., Yang, G.L., Nowinski, W.L., Sitoh, Y.Y., Low, C.M., Sim, K., 2013. GRIN2B gene and associated brain cortical white matter changes in bipolar disorder: a preliminary combined platform investigation. BioMed Res. Int. 2013, 635131.

Lee, K.W., Woon, P.S., Teo, Y.Y., Sim, K., 2012. Genome wide association studies (GWAS) and copy number variation (CNV) studies of the major psychoses: what have we learnt? Neurosci. Biobehav. Rev. 36, 556-571.

Lelli-Chiesa, G., Kempton, M.J., Jogia, J., Tatarelli, R., Girardi, P., Powell, J., Collier, D.A., Frangou, S., 2011. The impact of the Val158Met catechol-O-methyltransferase genotype on neural correlates of sad facial affect processing in patients with bipolar disorder and their relatives. Psychol. Med. 41, 779-788.

Lesch, K.P., Bengel, D., Heils, A., Sabol, S.Z., Greenberg, B.D., Petri, S., Benjamin, J., Muller, C.R., Hamer, D.H., Murphy, D.L., 1996. Association of anxiety-related traits with a polymorphism in the serotonin transporter gene regulatory region. Science (New York, N.Y.) 274, 1527-1531.

Leussis, M.P., Madison, J.M., Petryshen, T.L., 2012. Ankyrin 3: genetic association with bipolar disorder and relevance to disease pathophysiology. Biol. Mood Anxiety Disorders 2, 18.

Li, M., Chang, H., Xiao, X., 2016. BDNF Val66Met polymorphism and bipolar disorder in European populations: a risk association in case-control, family-based and GWAS studies. Neurosci. Biobehav. Rev. 68, 218-233.

Lim, C.S., Baldessarini, R.J., Vieta, E., Yucel, M., Bora, E., Sim, K., 2013. Longitudinal neuroimaging and neuropsychological changes in bipolar disorder patients: review of the evidence. Neurosci. Biobehav. Rev. 37, 418-435.

Linke, J., Witt, S.H., King, A.V., Nieratschker, V., Poupon, C., Gass, A., Hennerici, M.G., Rietschel, M., Wessa, M., 2011. Genome-wide supported risk variant for bipolar disorder alters anatomical connectivity in the human brain. Neuroimage 59, 3288-3296.

Lippard, E.T., Jensen, K.P., Wang, F., Johnston, J.A., Spencer, L., Pittman, B., Gelernter, J., Blumberg, H.P., 2016. Effects of ANK3 variation on gray and white matter in bipolar disorder. Mol. Psychiatry. http://dx.doi.org/10.1038/mp.2016.76. [Epub ahead of print]

Liu, X., Akula, N., Skup, M., Brotman, M.A., Leibenluft, E., McMahon, F.J., 2010. A genome-wide association study of amygdala activation in youths with and without bipolar disorder. J. Am. Acad. Child Adolesc. Psychiatry 49, 33-41.

Lopez, A.Y., Wang, X., Xu, M., Maheshwari, A., Curry, D., Lam, S., Adesina, A.M., Noebels, J.L., Sun, Q.Q., Cooper, E.C., 2016. Ankyrin-G isoform imbalance and interneuronopathy link epilepsy and bipolar disorder. Mol. Psychiatry. http://dx.doi. org/10.1038/mp.2016.233. [Epub ahead of print].

Lu, B., Gottschalk, W., 2000. Modulation of hippocampal synaptic transmission and plasticity by neurotrophins. Prog. Brain Res. 128, 231-241.

Macedo, D.S., Medeiros, C.D., Cordeiro, R.C., Sousa, F.C., Santos, J.V., Morais, T.A., Hyphantis, T.N., McIntyre, R.S., Quevedo, J., Carvalho, A.F., 2012. Effects of alphalipoic acid in an animal model of mania induced by D-amphetamine. Bipolar Disord. $14,707-718$.

Mallas, E., Carletti, F., Chaddock, C.A., Shergill, S., Woolley, J., Picchioni, M.M. McDonald, C., Toulopoulou, T., Kravariti, E., Kalidindi, S., Bramon, E., Murray, R., Barker, G.J., Prata, D.P., 2017a. The impact of CACNA1C gene, and its epistasis with ZNF804A, on white matter microstructure in health, schizophrenia and bipolar disorder. Genes Brain Behav. 16 (April (4)), 479-488.

Mallas, E.J., Carletti, F., Chaddock, C.A., Woolley, J., Picchioni, M.M., Shergill, S.S., Kane, F., Allin, M.P., Barker, G.J., Prata, D.P., 2016b. Genome-wide discovered psychosisrisk gene ZNF804A impacts on white matter microstructure in health, schizophrenia and bipolar disorder. PeerJ 4, e1570.

Marballi, K., Cruz, D., Thompson, P., Walss-Bass, C., 2012. Differential neuregulin 1 cleavage in the prefrontal cortex and hippocampus in schizophrenia and bipolar disorder: preliminary findings. PLoS One 7, e36431.

Matsuo, K., Walss-Bass, C., Nery, F.G., Nicoletti, M.A., Hatch, J.P., Frey, B.N., Monkul, E.S., Zunta-Soares, G.B., Bowden, C.L., Escamilla, M.A., Soares, J.C., 2009. Neuronal correlates of brain-derived neurotrophic factor Val66Met polymorphism and morphometric abnormalities in bipolar disorder. Neuropsychopharmacology 34, 1904-1913.

McIntosh, A.M., Moorhead, T.W., McKirdy, J., Sussmann, J.E., Hall, J., Johnstone, E.C., Lawrie, S.M., 2007. Temporal grey matter reductions in bipolar disorder are associated with the BDNF Val66Met polymorphism. Mol. Psychiatry 12, 902-903.

Mechelli, A., Prata, D.P., Fu, C.H., Picchioni, M., Kane, F., Kalidindi, S., McDonald, C., Demjaha, A., Kravariti, E., Toulopoulou, T., Murray, R., Collier, D.A., McGuire, P.K., 2008. The effects of neuregulin1 on brain function in controls and patients with schizophrenia and bipolar disorder. Neuroimage 42, 817-826.

Mechelli, A., Prata, D., Papagni, S.A., Tognin, S., Kambeitz, J., Fu, C., Picchioni, M., Walshe, M., Toulopoulou, T., Bramon, E., Murray, R., McGuire, P., 2012. Genetic vulnerability to psychosis and cortical function: epistatic effects between DAAO and G72. Curr. Pharm. Des. 18, 510-517.

Mei, L., Nave, K.A., 2014. Neuregulin-ERBB signaling in the nervous system and neuropsychiatric diseases. Neuron $83,27-49$.
Merikangas, K.R., Jin, R., He, J.P., Kessler, R.C., Lee, S., Sampson, N.A., Viana, M.C., Andrade, L.H., Hu, C., Karam, E.G., Ladea, M., Medina-Mora, M.E., Ono, Y., PosadaVilla, J., Sagar, R., Wells, J.E., Zarkov, Z., 2011. Prevalence and correlates of bipolar spectrum disorder in the world mental health survey initiative. Arch. Gen. Psychiatry 68, 241-251.

Mirakhur, A., Moorhead, T.W., Stanfield, A.C., McKirdy, J., Sussmann, J.E., Hall, J., Lawrie, S.M., Johnstone, E.C., McIntosh, A.M., 2009. Changes in gyrification over 4 years in bipolar disorder and their association with the brain-derived neurotrophic factor valine(66) methionine variant. Biol. Psychiatry 66, 293-297.

Miskowiak, K.W., Carvalho, A.F., 2014. 'Hot' cognition in major depressive disorder: a systematic review. CNS Neurol. Disord. Drug Targets 13, 1787-1803.

Miskowiak, K.W., Kjaerstad, H.L., Meluken, I., Petersen, J.Z., Maciel, B.R., Kohler, C.A., Vinberg, M., Kessing, L.V., Carvalho, A.F., 2016. The search for neuroimaging and cognitive endophenotypes: a critical systematic review of studies involving unaffected first-degree relatives of individuals with bipolar disorder. Neurosci. Biobehav. Rev. 73, 1-22.

Moher, D., Liberati, A., Tetzlaff, J., Altman, D.G., 2010. Preferred reporting items for systematic reviews and meta-analyses: the PRISMA statement. Int. J. Surg. (London, England) 8, 336-341.

Mostaid, M.S., Lloyd, D., Liberg, B., Sundram, S., Pereira, A., Pantelis, C., Karl, T., Weickert, C.S., Everall, I.P., Bousman, C.A., 2016. Neuregulin-1 and schizophrenia in the genome-wide association study era. Neurosci. Biobehav. Rev. 68, 387-409.

Muhleisen, T.W., Leber, M., Schulze, T.G., Strohmaier, J., Degenhardt, F., Treutlein, J., Mattheisen, M., Forstner, A.J., Schumacher, J., Breuer, R., Meier, S., Herms, S., Hoffmann, P., Lacour, A., Witt, S.H., Reif, A., Muller-Myhsok, B., Lucae, S., Maier, W., Schwarz, M., Vedder, H., Kammerer-Ciernioch, J., Pfennig, A., Bauer, M., Hautzinger, M., Moebus, S., Priebe, L., Czerski, P.M., Hauser, J., Lissowska, J., SzeszeniaDabrowska, N., Brennan, P., McKay, J.D., Wright, A., Mitchell, P.B., Fullerton, J.M., Schofield, P.R., Montgomery, G.W., Medland, S.E., Gordon, S.D., Martin, N.G., Krasnow, V., Chuchalin, A., Babadjanova, G., Pantelejeva, G., Abramova, L.I., Tiganov, A.S., Polonikov, A., Khusnutdinova, E., Alda, M., Grof, P., Rouleau, G.A., Turecki, G., Laprise, C., Rivas, F., Mayoral, F., Kogevinas, M., Grigoroiu-Serbanescu, M., Propping, P., Becker, T., Rietschel, M., Nothen, M.M., Cichon, S., 2014. Genomewide association study reveals two new risk loci for bipolar disorder. Nat. Commun. $5,3339$.

Murphy, S.E., Norbury, R., Godlewska, B.R., Cowen, P.J., Mannie, Z.M., Harmer, C.J., Munafo, M.R., 2013. The effect of the serotonin transporter polymorphism (5HTTLPR) on amygdala function: a meta-analysis. Mol. Psychiatry 18, 512-520.

Nortje, G., Stein, D.J., Radua, J., Mataix-Cols, D., Horn, N., 2013. Systematic review and voxel-based meta-analysis of diffusion tensor imaging studies in bipolar disorder. J. Affect. Disord. 150, 192-200.

Notaras, M., Hill, R., van den Buuse, M., 2015a. The BDNF gene Val66Met polymorphism as a modifier of psychiatric disorder susceptibility: progress and controversy. Mol. Psychiatry 20, 916-930.

Notaras, M., Hill, R., van den Buuse, M., 2015b. A role for the BDNF gene Val66Met polymorphism in schizophrenia: a comprehensive review. Neurosci. Biobehav. Rev. $51,15-30$.

Nurnberger Jr., J.I., Koller, D.L., Jung, J., Edenberg, H.J., Foroud, T., Guella, I., Vawter, M.P., Kelsoe, J.R., 2014. Identification of pathways for bipolar disorder: a metaanalysis. JAMA Psychiatry 71, 657-664.

Oertel-Knochel, V., Lancaster, T.M., Knochel, C., Stablein, M., Storchak, H., Reinke, B., Jurcoane, A., Kniep, J., Prvulovic, D., Mantripragada, K., Tansey, K.E., O'Donovan, M.C., Owen, M.J., Linden, D.E., 2015. Schizophrenia risk variants modulate white matter volume across the psychosis spectrum: evidence from two independent cohorts. Neuroimage Clin. 7, 764-770.

Olsson, C.A., Foley, D.L., Parkinson-Bates, M., Byrnes, G., McKenzie, M., Patton, G.C., Morley, R., Anney, R.J., Craig, J.M., Saffery, R., 2010. Prospects for epigenetic research within cohort studies of psychological disorder: a pilot investigation of a peripheral cell marker of epigenetic risk for depression. Biol. Psychol. 83, 159-165.

Ota, M., Hori, H., Sato, N., Yoshida, F., Hattori, K., Teraishi, T., Kunugi, H., 2016. The effects of ankyrin 3 gene risk variants on brain structures in patients with bipolar disorder and healthy subjects. Psychiatry Clin. Neurosci. 70, 498-506.

Ou, X., Crane, D.E., MacIntosh, B.J., Young, L.T., Arnold, P., Ameis, S., Goldstein, B.I., 2015. CACNA1C rs1006737 genotype and bipolar disorder: focus on intermediate phenotypes and cardiovascular comorbidity. Neurosci. Biobehav. Rev. 55, 198-210.

Papagni, S.A., Mechelli, A., Prata, D.P., Kambeitz, J., Fu, C.H., Picchioni, M., Walshe, M., Toulopoulou, T., Bramon, E., Murray, R.M., Collier, D.A., Bellomo, A., McGuire, P., 2011. Differential effects of DAAO on regional activation and functional connectivity in schizophrenia, bipolar disorder and controls. Neuroimage 56, 2283-2291.

Papiol, S., Molina, V., Desco, M., Rosa, A., Reig, S., Sanz, J., Palomo, T., Fananas, L., 2008. Gray matter deficits in bipolar disorder are associated with genetic variability at interleukin-1 beta gene (2q13). Genes Brain Behav. 7, 796-801.

Perrier, E., Pompei, F., Ruberto, G., Vassos, E., Collier, D., Frangou, S., 2011. Initial evidence for the role of CACNA1C on subcortical brain morphology in patients with bipolar disorder. Eur. Psychiatry 26, 135-137.

Piguet, C., Fodoulian, L., Aubry, J.M., Vuilleumier, P., Houenou, J., 2015. Bipolar disorder: functional neuroimaging markers in relatives. Neurosci. Biobehav. Rev. 57, 284-296.

Poletti, S., Locatelli, C., Radaelli, D., Lorenzi, C., Smeraldi, E., Colombo, C., Benedetti, F., 2014. Effect of early stress on hippocampal gray matter is influenced by a functional polymorphism in EAAT2 in bipolar disorder. Prog. Neuro-psychopharmacol. Biol. Psychiatry 51, 146-152.

Poletti, S., Aggio, V., Bollettini, I., Falini, A., Colombo, C., Benedetti, F., 2016. SREBF-2 polymorphism influences white matter microstructure in bipolar disorder. Psychiatry Res. Neuroimag. 257, 39-46.

Prata, D.P., Mechelli, A., Picchioni, M., Fu, C.H.Y., Kane, F., Kalidindi, S., McDonald, C., 
Kravariti, E., Toulopoulou, T., Bramon, E., Walshe, M., Murray, R., Collier, D.A., McGuire, P.K., 2011. No association of disrupted-in-schizophrenia-1 variation with prefrontal function in patients with schizophrenia and bipolar disorder. Genes Brain Behav. 10, 276-285.

Provenzi, L., Giorda, R., Beri, S., Montirosso, R., 2016. SLC6A4 methylation as an epigenetic marker of life adversity exposures in humans: a systematic review of literature. Neurosci. Biobehav. Rev. 71, 7-20.

Purcell, S., Neale, B., Todd-Brown, K., Thomas, L., Ferreira, M.A., Bender, D., Maller, J., Sklar, P., de Bakker, P.I., Daly, M.J., Sham, P.C., 2007. PLINK: a tool set for wholegenome association and population-based linkage analyses. Am. J. Hum. Genet. 81, 559-575.

Radua, J., Surguladze, S.A., Marshall, N., Walshe, M., Bramon, E., Collier, D.A., Prata, D.P., Murray, R.M., McDonald, C., 2013. The impact of CACNA1C allelic variation on effective connectivity during emotional processing in bipolar disorder. Mol. Psychiatry 18, 526-527.

Rasetti, R., Weinberger, D.R., 2011. Intermediate phenotypes in psychiatric disorders. Curr. Opin. Genet. Dev. 21, 340-348.

Rizzo, L.B., Costa, L.G., Mansur, R.B., Swardfager, W., Belangero, S.I., Grassi-Oliveira, R., McIntyre, R.S., Bauer, M.E., Brietzke, E., 2014. The theory of bipolar disorder as an illness of accelerated aging: implications for clinical care and research. Neurosci. Biobehav. Rev. 42, 157-169.

Roiser, J.P., Cannon, D.M., Gandhi, S.K., Taylor Tavares, J., Erickson, K., Wood, S., Klaver, J.M., Clark, L., Zarate Jr., C.A., Sahakian, B.J., Drevets, W.C., 2009. Hot and cold cognition in unmedicated depressed subjects with bipolar disorder. Bipolar Disord. 11, 178-189.

Rolstad, S., Sellgren Majkowitz, C., Joas, E., Ekman, C.J., Palsson, E., Landen, M., 2016. Polymorphisms of BDNF and CACNA1C are not associated with cognitive functioning in bipolar disorder or healthy controls. Cognit. Neuropsychiatry 21, 271-278.

Rosa, A.R., Singh, N., Whitaker, E., de Brito, M., Lewis, A.M., Vieta, E., Churchill, G.C., Geddes, J.R., Goodwin, G.M., 2014. Altered plasma glutathione levels in bipolar disorder indicates higher oxidative stress; a possible risk factor for illness onset despite normal brain-derived neurotrophic factor (BDNF) levels. Psychol. Med. 44, $2409-2418$.

Ruberto, G., Vassos, E., Lewis, C.M., Tatarelli, R., Girardi, P., Collier, D., Frangou, S., 2011. The cognitive impact of the ANK3 risk variant for bipolar disorder: initial evidence of selectivity to signal detection during sustained attention. PLoS One 6, e16671.

Rybakowski, J.K., Borkowska, A., Czerski, P.M., Skibinska, M., Hauser, J., 2003. Polymorphism of the brain-derived neurotrophic factor gene and performance on a cognitive prefrontal test in bipolar patients. Bipolar Disord. 5, 468-472.

Rybakowski, J.K., Borkowska, A., Skibinska, M., Szczepankiewicz, A., Kapelski, P., Leszczynska-Rodziewicz, A., Czerski, P.M., Hauser, J., 2006. Prefrontal cognition in schizophrenia and bipolar illness in relation to Val66Met polymorphism of the brainderived neurotrophic factor gene. Psychiatry Clin. Neurosci. 60, 70-76.

Scherk, H., Backens, M., Schneider-Axmann, T., Usher, J., Kemmer, C., Reith, W., Falkai, P., Gruber, O., 2009a. Cortical neurochemistry in euthymic patients with bipolar I disorder. World J. Biol. Psychiatry 10, 285-294.

Scherk, H., Gruber, O., Menzel, P., Schneider-Axmann, T., Kemmer, C., Usher, J., Reith, W., Meyer, J., Falkai, P., 2009b. 5-HTTLPR genotype influences amygdala volume.
Eur. Arch. Psychiatry Clin. Neurosci. 259, 212-217.

Shah, M.P., Wang, F., Kalmar, J.H., Chepenik, L.G., Tie, K., Pittman, B., Jones, M.M., Constable, R.T., Gelernter, J., Blumberg, H.P., 2009. Role of variation in the serotonin transporter protein gene (SLC6A4) in trait disturbances in the ventral anterior cingulate in bipolar disorder. Neuropsychopharmacology 34, 1301-1310.

Sklar, P., Smoller, J.W., Fan, J., Ferreira, M.A., Perlis, R.H., Chambert, K., Nimgaonkar, V.L., McQueen, M.B., Faraone, S.V., Kirby, A., de Bakker, P.I., Ogdie, M.N., Thase, M.E., Sachs, G.S., Todd-Brown, K., Gabriel, S.B., Sougnez, C., Gates, C., Blumenstiel, B., Defelice, M., Ardlie, K.G., Franklin, J., Muir, W.J., McGhee, K.A., MacIntyre, D.J., McLean, A., VanBeck, M., McQuillin, A., Bass, N.J., Robinson, M., Lawrence, J., Anjorin, A., Curtis, D., Scolnick, E.M., Daly, M.J., Blackwood, D.H., Gurling, H.M., Purcell, S.M., 2008. Whole-genome association study of bipolar disorder. Mol. Psychiatry 13, 558-569.

Smoller, J.W., Finn, C.T., 2003. Family, twin, and adoption studies of bipolar disorder. Am. J. Med. Genet. C Semin. Med. Genet. 123c, 48-58.

Soeiro-de-Souza, M.G., Otaduy, M.C., Dias, C.Z., Bio, D.S., Machado-Vieira, R., Moreno, R.A., 2012. The impact of the CACNA1C risk allele on limbic structures and facial emotions recognition in bipolar disorder subjects and healthy controls. J. Affect. Disord. 141, 94-101.

Tesli, M., Egeland, R., Sonderby, I.E., Haukvik, U.K., Bettella, F., Hibar, D.P., Thompson, P.M., Rimol, L.M., Melle, I., Agartz, I., Djurovic, S., Andreassen, O.A., 2013. No evidence for association between bipolar disorder risk gene variants and brain structural phenotypes. J. Affect. Disord. 151, 291-297.

Tramontina, J.F., Yates, D., Magalhaes, P.V., Trentini, C., Sant'anna, M.K., Fries, G.R., Bock, H., Saraiva-Pereira, M.L., Kapczinski, F., 2009. Brain-derived neurotrophic factor gene val66met polymorphism and executive functioning in patients with bipolar disorder. Revista brasileira de psiquiatria (Sao Paulo, Brazil: 1999) 31, $136-140$.

Vieta, E., 2015. [Personalised medicine applied to mental health: precision psychiatry]. Revista de psiquiatria y salud mental 8, 117-118.

Wegbreit, E., Cushman, G.K., Puzia, M.E., Weissman, A.B., Kim, K.L., Laird, A.R., Dickstein, D.P., 2014. Developmental meta-analyses of the functional neural correlates of bipolar disorder. JAMA Psychiatry 71, 926-935.

Winterer, G., Konrad, A., Vucurevic, G., Musso, F., Stoeter, P., Dahmen, N., 2008. Association of 5' end neuregulin-1 (NRG1) gene variation with subcortical medial frontal microstructure in humans. Neuroimage 40, 712-718.

Wolf, C., Mohr, H., Schneider-Axmann, T., Reif, A., Wobrock, T., Scherk, H., Kraft, S., Schmitt, A., Falkai, P., Gruber, O., 2014. CACNA1C genotype explains interindividual differences in amygdala volume among patients with schizophrenia. Eur. Arch. Psychiatry Clin. Neurosci. 264, 93-102.

Zeni, C.P., Mwangi, B., Cao, B., Hasan, K.M., Walss-Bass, C., Zunta-Soares, G., Soares, J.C., 2016. Interaction between BDNF rs6265 Met allele and low family cohesion is associated with smaller left hippocampal volume in pediatric bipolar disorder. J. Affect. Disord. 189, 94-97.

Zuliani, R., Moorhead, T.W., Job, D., McKirdy, J., Sussmann, J.E., Johnstone, E.C., Lawrie, S.M., Brambilla, P., Hall, J., McIntosh, A.M., 2009. Genetic variation in the G72 (DAOA) gene affects temporal lobe and amygdala structure in subjects affected by bipolar disorder. Bipolar Disord. 11, 621-627. 